\title{
Chronic Glutamate Toxicity in Neurodegenerative Diseases-What is the Evidence?
}

\author{
Jan Lewerenz ${ }^{1 *}$ and Pamela Maher ${ }^{2 *}$ \\ ${ }^{1}$ Department of Neurology, Ulm University, Ulm, Germany, ${ }^{2}$ Cellular Neurobiology Laboratory, Salk Institute for Biological \\ Studies, La Jolla, CA, USA
}

OPEN ACCESS

Edited by:

Irving E. Vega,

Michigan State University, USA

Reviewed by:

Marco Aurelio M. Freire,

State University of Rio Grande do

Norte, Brazil

James C. Vickers,

University of Tasmania, Australia

*Correspondence:

Jan Lewerenz

jan.lewerenz@gmail.com;

Pamela Maher

pmaher@salk.edu

Specialty section:

This article was submitted to

Neurodegeneration,

a section of the journal

Frontiers in Neuroscience

Received: 25 September 2015

Accepted: 24 November 2015

Published: 16 December 2015

Citation:

Lewerenz J and Maher P (2015)

Chronic Glutamate Toxicity in

Neurodegenerative Diseases - What is

the Evidence? Front. Neurosci. 9:469.

doi: 10.3389/fnins.2015.00469
Together with aspartate, glutamate is the major excitatory neurotransmitter in the brain. Glutamate binds and activates both ligand-gated ion channels (ionotropic glutamate receptors) and a class of G-protein coupled receptors (metabotropic glutamate receptors). Although the intracellular glutamate concentration in the brain is in the millimolar range, the extracellular glutamate concentration is kept in the low micromolar range by the action of excitatory amino acid transporters that import glutamate and aspartate into astrocytes and neurons. Excess extracellular glutamate may lead to excitotoxicity in vitro and in vivo in acute insults like ischemic stroke via the overactivation of ionotropic glutamate receptors. In addition, chronic excitotoxicity has been hypothesized to play a role in numerous neurodegenerative diseases including amyotrophic lateral sclerosis, Alzheimer's disease and Huntington's disease. Based on this hypothesis, a good deal of effort has been devoted to develop and test drugs that either inhibit glutamate receptors or decrease extracellular glutamate. In this review, we provide an overview of the different pathways that are thought to lead to an over-activation of the glutamatergic system and glutamate toxicity in neurodegeneration. In addition, we summarize the available experimental evidence for glutamate toxicity in animal models of neurodegenerative diseases.

Keywords: glutamate receptors, glutamate transporters, system $\mathbf{x}_{c}^{-}$, Alzheimer's disease, Huntington's disease, amyotrophic lateral sclerosis, neurodegeneration, excitotoxicity

\section{INTRODUCTION}

L-glutamate (L-glu) is the major excitatory neurotransmitter in the brain and is functionally involved in virtually all activities of the nervous system. In this section, we will first outline the general principles of L-glu signaling in the brain. Then, we will broaden this scheme by expanding the model to (a) different pools of extracellular glutamate (synaptic, perisynaptic, and extrasynaptic) resulting from either vesicular and non-vesicular sources or atypically located glutamate receptors outside of synapses and (b) other molecules present in the brain that have the ability to activate glutamate receptors and discuss their possible physiological functions.

\section{Glutamate Signaling in the Brain}

The human brain contains 6-7 $\mu \mathrm{mol} / \mathrm{g}$ wet weight of L-glu (Perry et al., 1971; Lefauconnier et al., 1976). Thus, L-glu along with glutamine is the most abundant free amino acid in the central nervous system. More than five decades ago, Curtis et al. demonstrated that L-glu has an excitatory action 
on nerve cells (Curtis et al., 1960). Since then, its role as an excitatory neurotransmitter as well as its cerebral metabolism have been studied in detail (reviewed by Fonnum, 1984; Hertz, 2006; Marmiroli and Cavaletti, 2012; Zhou and Danbolt, 2014).

L-glu is concentrated in synaptic vesicles in the presynaptic terminal by the action of vesicular glutamate transporters (vGLUT; Takamori, 2006). In addition, some of the L-glu in the vesicles might be generated by a vesicle-associated aspartate amino transferase from 2-oxoglutarate using L-aspartate (Lasp) as the amino group donor (Takeda et al., 2012). Upon depolarization of the presynaptic membrane, L-glu is released into the synaptic cleft and binds to ionotropic glutamate receptors (iGluRs) at the postsynaptic membrane (Figure 1). iGluRs are ligand-gated ion channels and include receptors of the $\alpha$-amino-3-hydroxy-5-methyl-4-isoxazolepropionic acid (AMPA), kainate, and N-methyl-D-aspartic acid (NMDA) types (reviewed in Lodge, 2009). While AMPA and kainate receptors primarily mediate sodium influx, NMDA receptors have high calcium conductivity. Activation of NMDA receptors plays an important role in synaptic plasticity and learning (reviewed in Miyamoto, 2006). In contrast to the other iGluRs, the activity of NMDA receptors is inhibited by a so-called $\mathrm{Mg}^{+2}$ block at the regular membrane potential but the ion channel is readily de-blocked by membrane depolarization, which removes $\mathrm{Mg}^{+2}$ from the pore (Vargas-Caballero and Robinson, 2004). NMDA receptors are tetramers containing two NR1 subunits and two NR2 or NR3 subunits (Paoletti and Neyton, 2007).

In addition to iGluRs, eight isoforms of metabotropic glutamate receptors (mGluRs; Spooren et al., 2010) exist, which belong to the family of G-protein-coupled receptors and do not form ion channels but rather signal via various second messenger systems (reviewed in Spooren et al., 2010). L-glu-induced depolarization leads to a postsynaptic excitatory potential which facilitates the generation of an action potential at the axon hillock. The glutamatergic synapse is ensheathed by astrocytic processes that express high levels of excitatory amino acid transporters (EAATs; Chaudhry et al., 1995). Five different EAATs exist, EAAT1-5, of which EAAT1 and 2 are the primary astrocytic EAATs, whereas EAAT3 shows a predominantly neuronal

\footnotetext{
Abbreviations: $\mathrm{A} \beta$, amyloid beta; $\mathrm{AD}$, Alzheimer's disease; ADME, absorption, distribution, metabolism, and excretion; ALS, amyotrophic lateral sclerosis; ALS/PDC, Guamian amyotrophic lateral sclerosis/Parkinson-dementia complex; AMPA, $\alpha$-amino-3-hydroxy-5-methyl-4-isoxazolepropionic acid; ANA, anthranilic acid; APP, amyloid precursor protein; Asc-1, alanine-serine-cysteine amino acid transporter 1; L-asp, aspartate; BMAA, $\beta$ - $N$-methylamino-Lalanine; BOAA, $\beta-N$-oxalylamino-L-alanine; Cef, ceftriaxone; CREB, cyclicAMP response element-binding protein; CSF, cerebral spinal fluid; CNS, central nervous system; DAO, D-amino acid oxidase; DIV, days in vitro; EAAT, excitatory amino acid transporter; GFAP, glial fibrillary acidic protein; iGluR, ionotropic glutamate receptor; L-glu, glutamate; 3HANA, 3-hydroxyanthranilic acid; 3-HAO, 3-hydroxyanthranilate oxidase; L-HCA, homocysteate; HD, Huntington's disease; 3HK, 3-hydroxykynurenine; Htt, huntingtin protein; IDO, indoleamine 2,3-dioxygenase; KAT, kynurenine aminotransferase; KMO, kynurenine monoxygenase; KYN, kynurenine; KYNA, kynurenic acid; MAPK, mitogen activate protein kinase; mGluR, metabotropic glutamate receptors; MSN, medium spiny neurons; NMDA, N-methyl-D-aspartic acid; QUIN, quinolinic acid; SOD1, superoxide dismutase 1; SSZ, sulfasalazine; TBI, traumatic brain injury, Tg, transgenic, TSC, tuberous sclerosis complex; vGLUT, vesicular glutamate transporters; YAC, yeast artificial chromosome.
}

expression (Zhou and Danbolt, 2013). About 90\% of the L-glu transport is mediated by EAAT2 (aka GLT-1 in rodents). These transporters co-transport 2 or 3 molecules of $\mathrm{Na}^{+}$and a proton with each molecule of L-glu (or L-asp) in conjunction with the counter-transport of a $\mathrm{K}^{+}$ion (Zerangue and Kavanaugh, 1996). Thus, by using the electrochemical gradient of these ions across the plasma membrane as an energy source, the transporters are capable of effectively accumulating L-glu and L-asp in cells against their steep intra- to extracellular concentration gradients. This allows the brain to maintain a very low extracellular Lglu concentration in the low micromolar range (Baker et al., 2003; De Bundel et al., 2011). It is generally thought that L-glu taken up by astrocytes is converted to glutamine by the enzyme glutamine synthetase, the glutamine is then released, taken up by neurons and converted to L-glu and used once again for neurotransmission (Coulter and Eid, 2012).

\section{The Role of Extrasynaptic Glutamate in the Brain}

Apart from the role of L-glu as the principal excitatory neurotransmitter released from glutamatergic presynapses as described above, it has become apparent that L-glu receptors outside the synaptic cleft also play an important role in brain physiology (Papouin and Oliet, 2014). In the cerebellum, it was demonstrated by analyzing AMPA receptor-mediated currents in Bergmann glia that synaptically released L-glu concentrations can reach extrasynaptic concentrations of up to $190 \mu \mathrm{M}$, while concentrations in the synaptic cleft exceed $1 \mathrm{mM}$ (Dzubay and Jahr, 1999). Moreover, some mGluRs have been shown to exhibit a distinct localization in proximity to the postsynaptic density that would allow them to readily detect L-glu leaking from the synaptic cleft (Luján et al., 1997; Figure 1). However, in recent years, evidence has accumulated that iGluRs, especially of the NMDA type, are also present at extrasynaptic sites in the neuronal cell membrane (Papouin and Oliet, 2014). Using light and electron microscopy, Petralia et al. showed that extrasynaptic NMDA receptors cluster at distinct sites of close contact of the dendritic shaft with either axons, axon terminals, or astrocytic processes (Petralia et al., 2010). The proportion of extrasynaptic NMDA receptors was estimated to be as high as $36 \%$ of the dendritic NMDA receptor pool in rat hippocampal slices (Harris and Pettit, 2007). Although extrasynaptic NMDA receptors were associated with similar scaffolding proteins as synaptic NMDA receptors (Petralia et al., 2010), an in vitro study suggested that extrasynaptic and synaptic NMDA receptors may activate different downstream signaling pathways with contrasting results: suppression of CREB activity by extrasynaptic NMDA receptor activation but activation by synaptic NMDA receptors (Hardingham et al., 2002). Functionally, NMDA receptors localized extrasynaptically on dendritic shafts bind extrasynaptic L-glu and mediate $\mathrm{Ca}^{2+}$ influx upon relief of the $\mathrm{Mg}^{+2}$ block by dendrite depolarization upon backfiring of action potentials (Wu et al., 2012). Angulo et al. showed that L-glu release from astrocytes can activate so-called slow inward currents via extrasynaptic NMDAR receptors in CA1 neurons which thereby can be synchronized (Angulo et al., 2004). Thus, the mechanisms through which glial cells release L-glu as well 


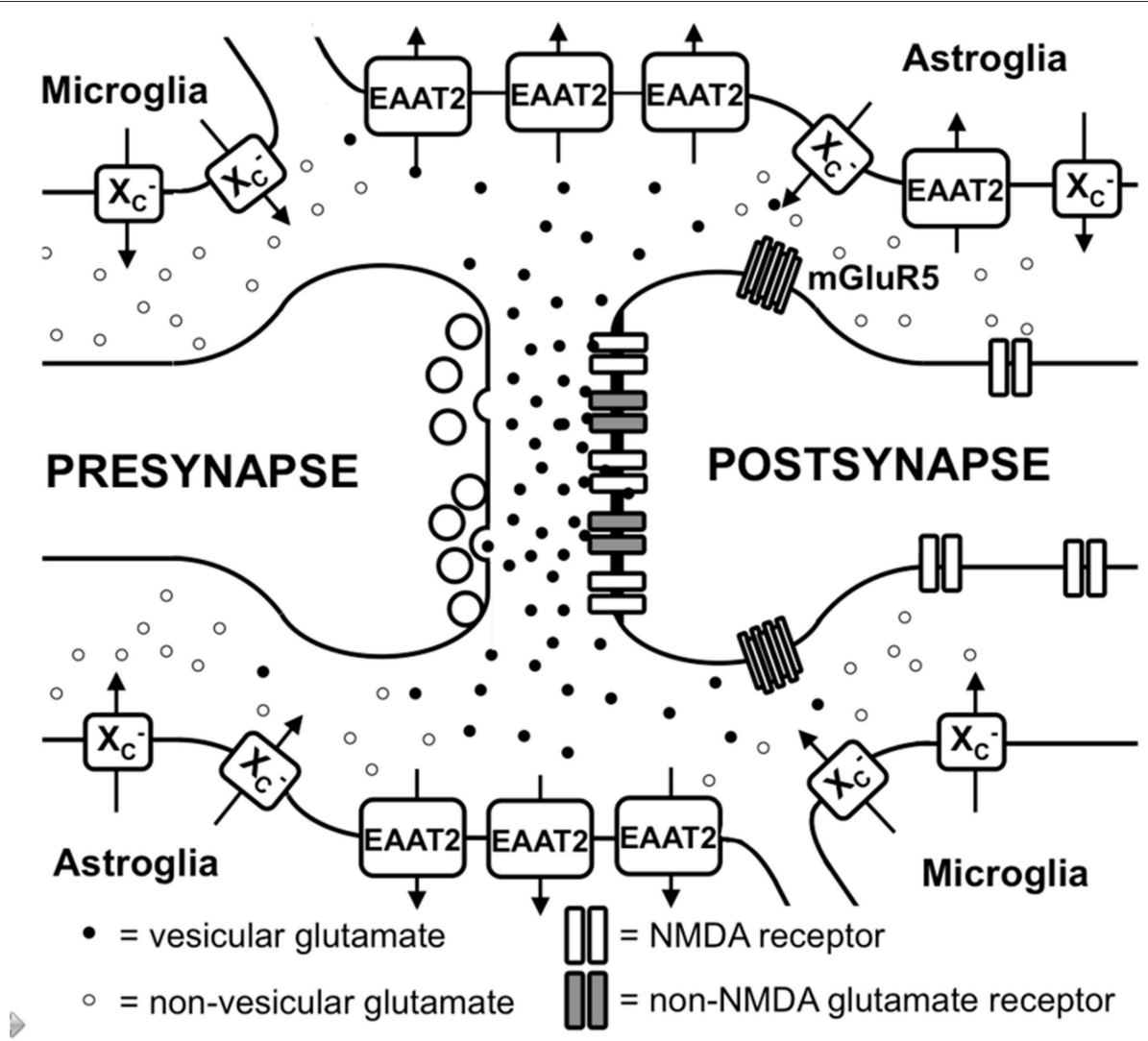

FIGURE 1 | Glutamate metabolism in the brain. Vesicular glutamate is synaptically released and binds to ionotropic glutamate receptors at the postsynapse. Glutamate is rapidly taken up by astrocytic glutamate transporters, especially EAAT2. Spillover from the synaptic cleft can activate perisynaptic mGluR5. Migroglia and astrocytes non-vesicularly release glutamate into the extrasynaptic extracellular space via system $x_{C}^{-}\left(x_{C}^{-}\right)$where it can activate extrasynaptic NMDA receptors.

as how the extrasynaptic L-glu concentrations are regulated are pivotal to understanding how the activity of extrasynaptic NMDA receptors are regulated.

Different mechanisms through which astrocytes can release L-glu have been proposed: vesicular L-glu release (Adak et al., 2000) and non-vesicular release via anion channels (Wang et al., 2013) and connexin hemichannels (Stehberg et al., 2012) as well as release via the cystine/glutamate antiporter system $x_{c}^{-}$(Massie et al., 2015). Data by Wang et al. strongly suggest that vesicular release from astrocytes plays a minor role, as the $\mathrm{Ca}^{+2}$-mediated release of L-glu was still present in astrocytes derived from dominant-negative SNARE mice (Wang et al., 2013) where vesicular release can be blocked by doxycycline withdrawal (Pascual et al., 2005). System $\mathrm{x}_{\mathrm{c}}^{-}$ is a cystine/glutamate antiporter which belongs to the class of heterodimeric amino acid transporters, consisting of $\mathrm{xCT}$ as the specific subunit and $4 \mathrm{~F} 2 \mathrm{hc}$ as the promiscuous heavy chain (Sato et al., 1999). This transporter is expressed in the brain, especially in astroglial and microglial cells (Fogal et al., 2007; Mesci et al., 2015; Figure 1). The fact that extrasynaptic L-glu levels in different areas of the brain are downregulated by approximately $60-70 \%$ in xCT knock out mice (De Bundel et al., 2011; Massie et al., 2011) indicates that system $\mathrm{x}_{\mathrm{c}}^{-}$releases L-glu into the extrasynaptic space and demonstrates that this transporter is important in the regulation of extrasynaptic L-glu levels. This is further supported by the observation that when measured by in vivo microdialysis, the rise in extrasynaptic L-glu induced by EAAT inhibitors is neutralized by blocking system $\mathrm{x}_{\mathrm{c}}^{-}$while blocking neuronal vesicular L-glu release is ineffective (Baker et al., 2002; Melendez et al., 2005).

Taken together, glutamatergic neurotransmission not only occurs via classical excitatory synapses but also via extrasynaptic L-glu receptors (Figure 1). Moreover, the levels of extrasynaptic L-glu are determined, at least in part, by glial non-vesicular L-glu release (Figure 1). However, the regulation of extrasynaptic L-glu levels as well as its temporal-spatial dynamics and its impact on neuronal function, neurodegeneration, and behavior are far from being fully understood.

\section{Other Molecules that are Physiologically Present in the Brain and May Activate Glutamate Receptors}

Very early studies indicated that L-asp, like L-glu, has an excitatory action on neurons (Curtis et al., 1960). L-asp colocalizes with L-glu in the synaptic vesicles of asymmetric excitatory synapses (Gundersen et al., 1998). However, the total concentration in the brain $(0.96-1.62 \mu \mathrm{mol} / \mathrm{g}$ wet weight) 
(Perry et al., 1971; Lefauconnier et al., 1976), the extracellular concentrations in the cortex as measured by microdialysis (1.62 $\mu \mathrm{M}$ for L-asp and $9.06 \mu \mathrm{M}$ for L-glu) and its distribution as determined by immunohistochemistry (Gundersen et al., 1991) indicate that $\mathrm{L}$-asp is less abundant that $\mathrm{L}$-glu. However, $\mathrm{L}$-asp is a potent agonist on NMDA receptors but not other iGluRs with an $\mathrm{EC}_{50}$ only eight-fold higher than that of L-glu (Patneau and Mayer, 1990). EAATs that play an important role in the uptake of vesicularly released L-glu in the CNS (Tanaka et al., 1997; Petr et al., 2015) also avidly take up L-asp (Arriza et al., 1994). Thus, Lasp is probably not as important as L-glu with respect to the total excitatory tone mediated by iGluRs but must not be forgotten in this context. In addition to its role as a neurotransmitter, as mentioned above, L-asp is also required as a substrate for aspartate amino transferase that converts 2-oxoglutarate to L-glu for transport into the synaptic vesicles of glutamatergic neurons (Takeda et al., 2012) and thus might indirectly increase L-glu release.

One feature that distinguishes NMDA receptors from other iGluRs is that activation of NMDA receptors requires the binding of a co-agonist to the glycine binding site of the receptor (Johnson and Ascher, 1987). Within the spinal cord and the retina, the source of glycine might be spillover from glycinergic inhibitory synapses (Ahmadi et al., 2003; Kalbaugh et al., 2009). However, in other parts of the brain with high NMDA receptor expression, like the hippocampal formation (Monyer et al., 1994), responses mediated by strychnine-sensitive glycine receptors are absent, at least in adult neurons, indicating the lack of glycinergic inhibitory neurotransmission (Ito and Cherubini, 1991). However, glycine is present in the extracellular fluid in the hippocampus at baseline levels of approximately $1.5 \mu \mathrm{M}$ (Yamamoto et al., 2010), which is near the saturation of the glycine binding site of the NMDA receptor (Johnson and Ascher, 1987), but can be dynamically up- and down-regulated (Yamamoto et al., 2010). The source of extracellular glycine in the hippocampus might be neurons, which release glycine via the alanine-serine-cysteine amino acid transporter 1 (asc-1; Rosenberg et al., 2013). However, glycine release by astrocytes, which is stimulated by depolarization and kainate, has also been reported (Holopainen and Kontro, 1989).

Even very early studies of the NMDA receptor and its coactivation by glycine showed that D-amino acids, especially D-serine, are almost as effective as glycine (Kleckner and Dingledine, 1988). Only a few years later, it became apparent that $\mathrm{D}$-serine is present in rat and human brains at approximately one third of the concentration of L-serine with an absolute concentration of more that $0.2 \mu \mathrm{mol} / \mathrm{g}$ brain tissue (Hashimoto et al., 1992, 1993). Using an antiserum specific for D-serine, Schell et al. demonstrated that D-serine in the brain is exclusively localized in astrocytes and that its distribution matches the expression of NMDA receptors (Schell et al., 1995). Moreover, the same authors showed that D-serine is released from cultured astrocytes upon exposure to L-glu or kainate (Schell et al., 1995). The abundance of D-serine is determined by both the degrading enzyme D-amino acid oxidase (DAO), which shows high expression in the hindbrain, where $\mathrm{D}$-serine levels are low, and the synthetic enzyme serine racemase that generates D-serine from L-serine (Schell et al., 1995; Wolosker et al.,
1999). D-Serine seems to be stored in cytoplasmic vesicles in astrocytes and is released by exocytosis (Mothet et al., 2005). Long-term potentiation depends on D-serine release from astrocytes in hippocampal slices, indicating that this amino acid indeed plays an important role in glutamatergic neurotransmission via NMDA receptors (Henneberger et al., 2010). Also in hippocampal slices, Papouin et al. determined, using D-serine and glycine degrading enzymes, that D-serine serves as a co-transmitter for synaptic NMDA receptors on CA1 neurons whereas glycine serves as the endogenous co-agonist for extrasynaptic NMDA receptors (Papouin et al., 2012). This, however, is not a general rule as synaptic NMDA receptors of dentate gyrus neurons use glycine instead of $\mathrm{D}$-serine as the co-agonist (Le Bail et al., 2015).

Taken together, multilayered evidence suggests that not only L-asp acting as an agonist on NMDA receptors but also glycine as well as D-serine play important roles in glutamatergic neurotransmission in the brain. However, other molecules have also been proposed to be biologically relevant modulators of glutamatergic neurotransmission.

L-homocysteate (L-HCA) shares structural similarities with L-glu. This non-protein amino acid is an oxidation product of homocysteine (Frauscher et al., 1995) which is biosynthesized from methionine by the removal of its terminal methyl group and is an intermediate of the transsulfuration pathway through which methionine can be converted to cysteine via cystathionine (McBean, 2012). Early studies showed that this amino acid can induce calcium influx in cultured neurons as efficiently as L-glu (Berdichevsky et al., 1983). Indeed, L-HCA showed a high affinity for NMDA receptors as compared to other iGluRs in binding assays which correlated with its ability to induce NMDA receptor antagonist-inhibitable excitotoxicity and sodium influx (Pullan et al., 1987). In addition, L-HCA is able to activate mGluR5 as effectively as L-glu (Shi et al., 2003). L-HCA is present in the brain although the concentrations were found to be about 500 -fold lower than those of L-glu and 100-fold lower than those of L-asp in different areas of the rat brain (Kilpatrick and Mozley, 1986). Upon potassium-induced stimulation, L-HCA release is induced from brain slice preparations as observed for L-asp and L-glu although the absolute release of HCA is about 50-fold lower (Do et al., 1986). Interestingly, HCA is a highly effective competitive inhibitor of cystine and L-glu uptake via the cystine/glutamate antiporter system $\mathrm{x}_{\mathrm{c}}^{-}$(Bannai and Ishii, 1982; Patel et al., 2004), the activity of which regulates the extracellular extrasynaptic Lglu concentrations in the brain (De Bundel et al., 2011). Thus, the effect of L-HCA on the activation of NMDA and other L-glu receptors (Yuzaki and Connor, 1999) might also depend on the L-HCA-induced release of L-glu via system $\mathrm{x}_{\mathrm{c}}^{-}$. In summary, $\mathrm{L}-$ HCA may only play a limited role in the overall stimulatory input on L-glu receptors. However, this may change dramatically under some conditions, e.g., in patients with high-dose methotrexate therapy, an anticancer drug that, by inhibiting dihydrofolate reductase, inhibits the tetrahydrofolate-catalyzed recycling of methionine from homocysteine. Here, L-HCA concentrations of more than $100 \mu \mathrm{M}$ have been documented in the cerebrospinal fluid whereas L-HCA was undetectable in control subjects (Quinn et al., 1997). 


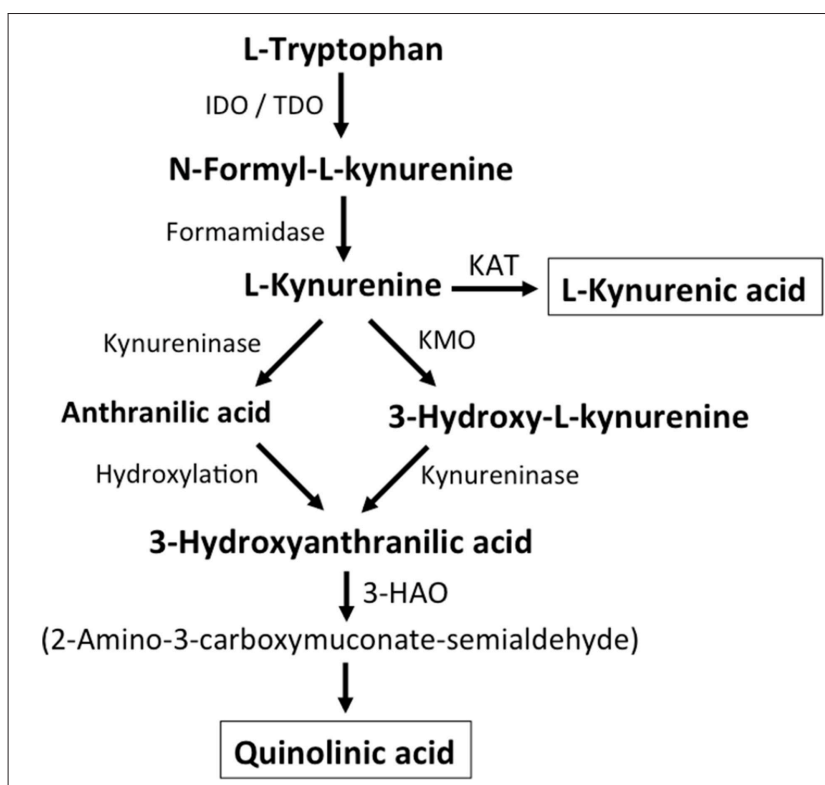

FIGURE 2 | Kynurenine metabolism. By either

indoleamine-2,3-dioxygenase (IDO) or tryptophan-2,3-dioxygenase (TDO), tryptophan is converted to $\mathrm{N}$-formyl-L-kynurenine, which is metabolized to L-kynurenine by formaminidase. L-kynurenine may be metabolized to kynurenic acid by kynurenine aminotransferase (KAT), to

3-hydroxy-L-kynurenine by kynurenine-3-monooxygenase or to anthranilic acid by kynureninase. 3-Hydroxy-L-kynurenine and anthranilic acid can both be converted to 3-hydroxyanthranilic acid. 3-Hydroxyanthranilate oxidase (3-HAO) metabolizes 3-hydroxyanthranilic acid to

2-amino-3-carboxymuconate-semialdehyde which is non-enzymatically converted to quinolinic acid. Inhibition of $\mathrm{KMO}$ results in increased production of kynurenic acid while the generation of quinolinic acid is inhibited (modified from Vécsei et al., 2013).

Additional endogenous small molecules that are thought to interfere with L-glu signaling are several intermediates of tryptophan metabolism (Vécsei et al., 2013; Figure 2). Via the action of indoleamine 2,3-dioxygenase (IDO) or tryptophan 2,3-dioxygenase (TDO), tryptophan is converted to N-formylL-kynurenine, which is then converted to kynurenine (KYN) by formamidase. From here three pathways, two of which merge at a later step, lead to further metabolism. First, via the action of kynurenine aminotransferase (KAT), KYN is converted to kynurenic acid (KYNA). KYN also can be converted to 3-hydroxykynurenine (3HK) by kynurenine monooxygenase (KMO), which can then be used as a substrate by kynureninase for the synthesis of 3-hydroxyanthranilic acid (3HANA). In addition, using KYN as a substrate, kynureninase produces anthranilic acid (ANA), which by non-specific hydroxylation can also be converted to 3HANA. 3HANA finally serves a substrate for the generation of quinolinic acid (QUIN).

The tryptophan concentration in rat brain is about $25 \mathrm{nmol} / \mathrm{g}$ wet weight and thus about 400-fold less than L-glu and 100-fold less than L-asp (Gál and Sherman, 1978; Kilpatrick and Mozley, 1986). The reported brain concentrations of kynurenines are even lower with $0.4-1.6 \mathrm{nmol} / \mathrm{g}$ for QUIN (Wolfensberger et al., 1983), 0.01-0.07 nmol/ml for KYNA (Moroni et al., 1988), and $0.016 \mathrm{nmol} / \mathrm{g}$ for 3HANA (Baran and Schwarcz, 1990). About
$40 \%$ of brain KYN is locally synthesized (Gál and Sherman, 1978). The different metabolites of tryptophan show differential binding to plasma proteins and their transport via the bloodbrain barrier is very different. $\mathrm{KYN}$ and $3 \mathrm{HK}$ are transported via the large neutral amino acid carrier system L (Fukui et al., 1991). Other kynurenines seem to enter the brain by passive diffusion. In addition, ANA, 3HANA and especially KYNA avidly bind to serum proteins, which limit their diffusibility across the blood-brain barrier.

As early as 1982, it was found that QUIN, when ionophoretically applied to rat cortex, induced neuronal firing that was inhibited by an NMDA receptor antagonist (Birley et al., 1982), indicating that QUIN may act as an NMDA receptor agonist. However, the $\mathrm{EC}_{50}$ for QUIN to activate NMDA receptor currents has been shown to be approximately 1000-fold higher than the $\mathrm{EC}_{50}$ of L-glu (Patneau and Mayer, 1990). Of note, intracerebral injection of QUIN has been shown to induce ultrastructural, neurochemical, and behavioral changes very similar to those induced by NMDA receptor agonists (Schwarcz et al., 1983). However, the fact that QUIN concentrations are about 5000- to 15,000-fold lower than cerebral L-glu concentrations makes it highly unlikely that modulation of NMDA receptor signaling by QUIN plays a significant role. KYNA was reported to act as an NMDA receptor antagonist (Ganong et al., 1983; Ganong and Cotman, 1986). However, although infusion with the KMO inhibitor Ro 61-8048 increased cerebral extracellular KYNA concentrations 10-fold, this did not lead to an inhibition of NMDA-mediated neuronal depolarization, a finding that challenges the notion that KYNA at near physiological levels directly modulates NMDA receptors (Urenjak and Obrenovitch, 2000). In contrast, increased KYNA in the brain induced by the KMO inhibitor JM6 decreased the extracellular cerebral L-glu concentration (Zwilling et al., 2011). In addition, KYNA levels in the extracellular cerebral fluid highly correlated with L-glu levels indicating that even at physiological or near physiological levels KYNA modulates L-glu metabolism (Zwilling et al., 2011). Both activation of the G-protein-coupled receptor GPR35 (Berlinguer-Palmini et al., 2013) and inhibition of presynaptic $\alpha 7$ nicotinic acetylcholine receptors have been implicated in the KYNA-induced reduction in L-glu release (Carpenedo et al., 2001). To summarize, although L-HCA and QUIN are present in the brain, their low concentrations speak against them having prominent roles in regulating glutamatergic neurotransmission. In contrast, although the pathways still have to be defined in more detail, evidence supports the view that KYNA can modulate L-glu release and thereby L-glu levels and neurotransmission.

\section{THE CONCEPTS OF ACUTE AND CHRONIC GLUTAMATE TOXICITY}

The term excitotoxicity was first used by Olney (1986) to describe the ability of L-glu, as well as structurally related amino acids, to kill nerve cells, a process that has been proposed to take place not only in acute but also chronic diseases of the central nervous system (for reviews Choi, 1988; Meldrum 
and Garthwaite, 1990). Excitotoxicity results from the excessive activation of iGluRs and leads to a characteristic loss of postsynaptic structures including dendrites and cell bodies. There is a significant level of variation in the sensitivity of different nerve cells to the various iGluR agonists which is related to both the specific receptors expressed on the nerve cells as well as their distinct metabolisms. Moreover, the susceptibility of neurons to excitotoxicity can change tremendously with age. Acute excitotoxic nerve cell death is thought to occur in response to a variety of severe insults including cerebral ischemia, traumatic brain injury (TBI), hypoglycemia, and status epilepticus (Meldrum and Garthwaite, 1990; Meldrum, 1994). But what about neurodegenerative diseases where nerve cell death occurs over an extended period of time? Does chronic excitotoxicity also exist? In other words, could exposure of nerve cells to low but above normal concentrations of L-glu (or glutamatergic neurotransmission as a sum of the input via the various molecules involved as discussed above) over an extended period of time also eventually lead to nerve cell death?

Excitotoxicity was originally studied in animals but in order to understand the mechanisms underlying this process, cell culture models were developed (for review Choi, 1988). The basic cell culture model of acute excitotoxicity involves treating primary neurons in culture with L-glu or a specific iGluR agonist for a short time period (min) (e.g., Choi, 1992; Schubert and Piasecki, 2001) and then assessing downstream events at the time point that is most relevant for the study. For example, cell death is often determined after $24 \mathrm{~h}$. While these types of studies have been shown to be very useful for understanding the pathways involved in acute excitotoxicity, it has proven much more difficult to study chronic excitotoxicity in culture partly because it is not entirely clear how to define "chronic" in the context of cell culture. Does chronic mean a low dose given for $24 \mathrm{~h}$ rather than a higher dose given for $5-10 \mathrm{~min}$ or is it more complicated than that? In one of the few studies that attempted to develop a model of chronic excitotoxicity (Ha et al., 2009), it was shown that it is indeed more complicated with acute and chronic excitotoxicity appearing to be distinct processes. In this study, the authors used pure cultures of primary cortical neurons prepared from day 14 mouse embryos and treated them after 7 and 14 days in culture (DIV; Ha et al., 2009). For chronic excitotoxicity, the neurons were exposed to L-glu or NMDA for $24 \mathrm{~h}$ and for acute excitotoxicity for $10 \mathrm{~min}$. In both cases, cell death was measured after $24 \mathrm{~h}$. Surprisingly, the $\mathrm{EC}_{50}$ s for the toxicity of L-glu were lower for acute toxicity, especially in the $7 \mathrm{DIV}$ cultures, as compared to the $\mathrm{EC}_{50}$ s for chronic toxicity. In addition, it was found that a high cell culture density increased the sensitivity of the cells to acute but not chronic excitotoxicity. Further studies suggested that the lower sensitivity of the neurons to L-glu in the chronic excitotoxicity paradigm was due to the activation of mGluR1, consistent with earlier data on the neuroprotective effects of mGluR1 activation (Sagara and Schubert, 1998).

An alternative approach to studying chronic glutamate toxicity utilized organotypic spinal cord cultures in combination with L-glu uptake inhibitors (Rothstein et al., 1993). These spinal cord cultures, which were prepared from 8-day-old rat pups, can be maintained in culture for up to 3 months. Chronic inhibition of L-glu uptake with two different uptake inhibitors resulted in a persistent elevation of L-glu in the cell culture medium and timeand concentration-dependent motor neuron cell death. The highest concentration of uptake inhibitor increased extracellular L-glu levels at least 25 -fold and began to kill the cells within 1 week whereas a five-fold lower concentration raised extracellular L-glu levels eight-fold and cell death only began after 2-3 weeks of treatment. The toxicity was blocked by non-NMDA but not NMDA receptor antagonists as well as by inhibitors of Lglu synthesis or release. These experiments suggest that even moderately increased L-glu concentrations can induce toxicity.

In vivo approaches to studying chronic excitotoxicity have mainly relied on an approach analogous to that used with the spinal cord cultures. In the majority of these studies, one or more EAATs were transiently or permanently genetically eliminated and the effects on brain function examined. In the first of these studies that used rats (Rothstein et al., 1996), chronic intraventricular administration of antisense RNA was used to eliminate each of the three main EAATs (EAAT1, EAAT2, and EAAT3). The loss of either of the glial L-glu transporters (EAAT1 and EAAT2) but not the neuronal transporter (EAAT3) resulted in large increases in extracellular L-glu concentrations in the striatum after 7 days as determined by microdialysis (EAAT2, 32-fold increase; EAAT1, 13-fold increase). Treatment with either the EAAT1 or EAAT2 antisense oligonucleotides caused a progressive motor impairment whereas the EAAT3 antisense oligonucleotide mainly produced epilepsy. The loss of any of the three transporters produced clear evidence of neuronal damage in the striatum and hippocampus after 7 days of treatment although the effects of the EAAT1 and EAAT2 antisense oligonucleotides were much more dramatic, consistent with the large increases in extracellular L-glu brought about by treatment with these antisense oligonucleotides.

Quite different results were obtained with homozygous mice deficient in EAAT2 (Tanaka et al., 1997) or EAAT1 (Watase et al., 1998). Mice deficient in EAAT2 displayed spontaneous and generally lethal seizures with $50 \%$ dead by 6 weeks of age (Tanaka et al., 1997). Approximately $30 \%$ of the mice showed selective neuronal degeneration in the hippocampal CA1 region at 4-8 weeks of age. L-glu levels in the CA1 region of the hippocampus measured by microdialysis were $\sim$ threefold higher in the mutant mice as compared with the wild type mice (Mitani and Tanaka, 2003). In contrast, heterozygous EAAT2 knock-out mice have a normal lifespan and do not show hippocampal CA1 atrophy (Kiryk et al., 2008). However, they display some behavioral abnormalities suggestive of mild glutaminergic hyperactivity. While mice deficient in EAAT1, which is highly expressed in cerebellar astrocytes, did not show changes in cerebellar structure or obvious symptoms of cerebellar impairment such as ataxic gait, they were unable to adapt to more challenging motor tasks such as quickly running on the rotorod (Watase et al., 1998). Taken together, these results suggest that disruptions in glutamatergic homeostasis have a much greater impact when they occur in the adult animal rather than when they are present from conception. 
Tuberous sclerosis complex (TSC) is a multi-system genetic disease caused by mutation of either the TSC1 or TSC2 genes and characterized by severe neurological symptoms. Mice with inactivation of the TSC1 gene in glia have a $>75 \%$ decrease in the expression and function of EAAT1 and EAAT2 and develop seizures (Zeng et al., 2007). At 4 weeks of age, prior to the development of seizures in these mice, there was an $~ 50 \%$ increase in extracellular L-glu in the hippocampus of these mutant mice, as determined by microdialysis, which correlated with increases in markers of cell death in neurons in both the hippocampus and cortex. Using hippocampal slices from 2 to 4 week old mice, impairments in long-term potentiation were identified, which translated into functional deficits when juvenile mice were tested for spatial and contextual memory in the Morris water maze and fear conditioning assays, respectively.

In most of the studies described above, there was a large increase in extracellular L-glu which, when examined, led, in most cases to negative impacts on the function of specific neuronal populations. To determine the long-term effects of more moderate increases in extracellular glutamate, Bao et al. (2009) created transgenic ( $\mathrm{Tg}$ ) mice with extra copies of the gene for Glud1 specifically in neurons. The GLUD1 protein is a mitochondrial enzyme that converts L-glu to 2-oxoglutarate. Mitochondrial 2-oxoglutarate is transported to the cytoplasm of nerve terminals where it is converted back into L-glu and stored in synaptic vesicles thereby contributing to the pool of synaptically releasable L-glu (Palaiologos et al., 1988; Takeda et al., 2012). Nine month old Glud1 Tg mice showed an $~ 10 \%$ increase in L-glu in the hippocampus and striatum relative to wild type mice as determined using magnetic resonance spectroscopy. In addition, evoked L-glu release in the striatum was increased by $\sim 50 \%$. At $12-20$ months of age, the Glud1 Tg mice showed significant decreases in the numbers of neurons in the CA1 region of the hippocampus and granule cell layer of the dentate gyrus as well as an age-dependent loss of both dendrites and dendritic spines in the hippocampus. There was also a decrease in long-term potentiation following high frequency stimulation in hippocampal slices from the Tg mice as compared to the wild type mice. However, whether these alterations resulted in behavioral impairments was not examined. Analysis of the transcriptome of the Glud1 Tg mice as compared to wild type mice suggested that long-term moderate increases in extracellular L-glu result in both accelerated aging at the level of gene expression coupled with compensatory responses that protected against stress and/or promoted recovery (Wang et al., 2010).

In summary, increases in extracellular L-glu in vivo can affect nerve cell survival and brain function. The consequences seem to be highly dependent on the degree of L-glu increase but even a $10 \%$ increase appears to affect nerve cell structure and survival particularly in the context of aging suggesting that chronic excitotoxicity may be particularly relevant to age-related neurodegenerative diseases.

Plant-based toxins have provided additional evidence for chronic excitotoxicity. These include domoic acid, the cause of amnesiac shellfish poisoning, from the alga Pseudo-nitzschia (Grant et al., 2010), $\beta$-N-oxalylamino-L-alanine (BOAA), the cause of lathyrism, from the plant Lathyrus sativus (Ludolph and Spencer, 1995) and possibly $\beta-N$-methylamino-L-alanine (BMAA), a postulated cause of Guamian amyotrophic lateral sclerosis/Parkinson-dementia complex (ALS/PDC), from the cycad Cycas circinalis (Karamyan and Speth, 2008). Based on evidence from human, and in some cases animal, exposures that resulted in significant neurological damage, further studies on these toxins showed that they all act on L-glu receptors and induce both acute and chronic neurotoxicity.

Domoic acid binds with high affinity to AMPA-, kainate-, and NMDA-type iGluRs (Qiu et al., 2006). Both acute, highdose toxicity, which can include seizures and death as well as lower dose, chronic toxicity of domoic acid have been described in both humans and animals that consumed shellfish and other sea life that eat the alga and concentrate the toxin (Grant et al., 2010). Domoic acid-related neuropathology occurs mainly in the hippocampus and results in memory deficits which may be permanent (Grant et al., 2010). Studies in animals suggest that domoic acid toxicity can be progressive over time with a significant period of good health after exposure before the manifestation of delayed injury (Grant et al., 2010). Moreover, the toxicity appears to be exacerbated by increasing age (Qiu et al., 2006).

Lathyrism is a neurological condition that develops only after several months of ingestion of the grass pea and only when it constitutes at least $30 \%$ of a nutritionally-poor diet (Paleacu et al., 1999). BOAA binds preferentially to non-NMDA-type iGluR. In contrast to domoic acid, BOAA specifically and selectively targets the upper motor neurons resulting in spastic paraparesis (Ludolph and Spencer, 1995). Lathyrism is not associated with any cognitive problems (Paleacu et al., 1999).

BMAA, which is closely related to BOAA, binds to both NMDA-type and non-NMDA-type iGluRs (Lobner et al., 2007). In addition, it can both inhibit cystine uptake into cells via system $\mathrm{x}_{\mathrm{c}}^{-}$thereby promoting oxidative stress and, as it is a substrate inhibitor, promote L-glu release from cells via the same transporter, which can enhance excitotoxicity through activation of mGluR5 (Liu et al., 2009). While the evidence that it could be responsible for Guanamian ALS/PDC is still debatable after almost 50 years (Karamyan and Speth, 2008), oral administration of BMAA to macaques dose-dependently caused a motor system disorder with involvement of both the upper and lower motor neurons as well as the extrapyramidal system after 2-12 weeks of treatment (Spencer et al., 1987). Histological examination showed that the motor cortex was most affected followed by the spinal cord and then the substantia nigra, which was mostly spared. While these symptoms resembled the early stages of Guanamian ALS/PDC, the severe cognitive deficits associated with the disorder were not seen. However, this could be related to the relatively short treatment period, the relatively young age of the macaques and/or the nutritional adequacy of their diet.

In summary, several toxins that bind to iGluRs and have been shown to induce excitotoxicity in cell culture can cause slowly developing neurological problems in both humans and animals. Interestingly, each toxin appears to target a specific type of neuron, an effect that might be related to both the pharmacokinetic and ADME properties of the toxins, which have not yet been studied to any great extent. However, the data from 
these toxins supports the idea that chronic excitotoxicity exists in humans and could play a role in multiple neurological disorders.

Since iGluRs are found both in the synapse as well in extra-synaptic locations, there has been a great deal of effort devoted to determining if the location of the receptors impacts the toxicity of glutamate and related molecules. An influential study using primary neuronal cultures (Hardingham et al., 2002) suggested that synaptic and extrasynaptic NMDA receptors have counteracting effects on cell fate with nerve cell death being mainly mediated by extrasynaptic NMDA receptors. However, these results have not been reproduced in brain slices or in vivo (reviewed in Papouin and Oliet, 2014). Furthermore, several more recent studies using the same primary neuronal culture preparation protocol as the earlier study found either no difference between synaptic and extrasynaptic NMDA receptors in promoting excitotoxicity (reviewed in Papouin and Oliet, 2014) or found that both receptors were required for cell death (Zhou et al., 2013). Moreover, a number of studies that supported the idea that extrasynaptic NMDA receptors promote excitotoxicity relied on the NMDA receptor inhibitor memantine which was originally thought to specifically act on extrasynaptic NMDA receptors (Xia et al., 2010). However, more recent studies have shown that memantine can inhibit both synaptic and extrasynaptic NMDA receptors (Emnett et al., 2013). Together these results strongly suggest that both synaptic and extrasynaptic NMDA receptors can contribute to excitotoxicity but that the precise contribution of each may depend on the experimental and/or pathological conditions.

\section{EVIDENCE FOR GLUTAMATE DYSREGULATION AND EXCITOTOXICITY IN DIFFERENT NEURODEGENERATIVE DISEASES}

\section{Excitotoxicity in Acute Diseases of the CNS}

As mentioned above, excitotoxicity was initially defined as an acute insult to nerve cells that leads to cell death by excessive activation of iGluRs. Acute excitotoxicity is known to play an important role in specific CNS disorders including cerebral ischemia, TBI, and status epilepticus. However, the mechanisms underlying acute excitotoxicity differ slightly among these different disorders as described below.

During brain ischemia, the initiation of L-glu- (or L-asp-) mediated excitotoxicity occurs within minutes due to the rapid increase in extracellular cerebral L-glu (and L-asp; reviewed in Dirnagl et al., 1999). The sudden loss of the energy supply due to the shut down of blood flow to the brain leads to a breakdown of the neuronal and astroglial membrane potentials as the maintenance of these is energy-dependent. In neurons, the subsequent membrane depolarization leads to vesicular Lglu release. In addition, energy depletion and disruption of ionic homeostasis inhibits EAAT activity in astrocytes and may even induce a reversal in their action thereby leading to non-vesicular L-glu and L-asp release. The release of L-glu/L-asp (Graham et al., 1990) from these different sources leads to excitotoxicity, mostly by over-activation of iGluRs of the NMDA type as shown by the efficacy of NMDA antagonists in the acute phase in animal models of transient cerebral ischemia (Park et al., 1988; Bielenberg and Beck, 1991; Katsuta et al., 1995).

In TBI, the mechanical tissue damage and disruption of the blood-brain barrier is the initiator of acute secondary neurodegeneration, which, in addition to neuroinflammation and oxidative stress, is mediated by L-glu release from intracellular compartments and thus by acute excitotoxicity (reviewed in Freire, 2012). Accordingly, acute administration of the NMDA antagonist MK801 following TBI ameliorates neuronal loss and long-term behavioral abnormalities (Sönmez et al., 2015).

In status epilepticus, ongoing synchronized activity of excitatory neuronal networks with concurrent breakdown of inhibitory mechanisms is the primary source of increased Lglu (and L-asp) release. As the intensity of synchronous activity is dependent on the integration of a nerve cell into a specific neuronal network and the ability of a nerve cell to withstand excessive glutamatergic input depends, among other properties, on the expression pattern of iGluRs, a rather restricted and maturation-dependent degeneration of neuronal populations is induced by prolonged epileptic seizures (Sankar et al., 1998). The relevance of excitotoxicity in status epilepticus is demonstrated by the fact that NMDA antagonists like ketamine reduce neuronal loss (Loss et al., 2012).

\section{Chronic Excitotoxicity during Progressive Long-Term Neurodegeneration}

As compared to acute insults to the CNS, in chronic neurodegenerative diseases the situation is much more complex. First, although compromised mitochondrial function has been repeatedly described in several neurodegenerative diseases (reviewed in Johri and Beal, 2012), the resulting impairments in energy supply are not nearly as severe as the energy failure in ischemic stroke. Thus, if excitotoxicity contributes to neurodegeneration, a very different time course of chronic excitotoxicity has to be assumed. In the following paragraphs, we will summarize what is known about the different pathways that might contribute to excitotoxicity in neurodegenerative diseases. We will focus on amyotrophic lateral sclerosis (ALS), Alzheimer's disease (AD) and Huntington's disease (HD) as important examples with sufficiently validated animal models.

\section{Amyotrophic Lateral Sclerosis}

ALS is a neurodegenerative disease where the degeneration of motor neurons dominates the clinical presentation and the course of the disease, which is fatal within a few years from onset. It is hypothesized that L-glu excitotoxicity plays a role in the motor neuron death in ALS as these cells express high levels of calcium-permeable AMPA receptors (Carriedo et al., 1996) and low levels of calcium binding proteins (Leal and Gomes, 2015). In contrast to the application of AMPA and kainate, as well as L$\mathrm{HCA}$, to the lumbar spinal cord of rats, treatment with NMDA spared motor neurons, indicating that NMDA excitotoxicity might not play a prominent role in ALS (Ikonomidou et al., 1996). However, NMDA receptor-mediated excitotoxicity in motor neurons was documented in chick embryo organotypic 
slice cultures (Brunet et al., 2009). Electrophysiological studies indicated that there is a transient hyperexcitability of motor neurons in the presymptomatic stage of ALS in mice transgenic for the G93A mutation of human SOD1 that is associated with hereditary ALS (Fuchs et al., 2013). In addition, a cortical hyperexcitability has been documented in familial and sporadic ALS patients that precedes the onset of clinical symptoms in familial ALS mutation carriers (Vucic et al., 2008). Finally, the only approved drug to treat ALS, which increases survival by 2-3 months (Miller et al., 2012), acts as an inhibitor of NMDA and kainate receptors (Debono et al., 1993) as well as rapidly upregulating EAAT activity in synaptosomes (Azbill et al., 2000).

In autopsied spinal cord from patients with ALS, several groups reported a pronounced reduction of EAAT2 but not EAAT1 protein expression in the gray matter in areas with significant motor neuron loss (Sasaki et al., 2000). In addition, both L-glu uptake as well as EAAT2 immunoreactivity, as analyzed by Western blotting, were shown to be quantitatively reduced in postmortem tissue of ALS patients especially in the spinal cord, the tissue that is most affected by the disease (Rothstein et al., 1992; Lin et al., 1998). Moreover, it was reported that as a potential consequence of EAAT2 downregulation, L-glu levels are increased in the CSF in patients with ALS (Rothstein et al., 1990). However, this finding could not be replicated by others (Perry et al., 1990).

The downregulation of EAAT2 in human ALS is recapitulated in several animal models of ALS including transgenic mice expressing human SOD1 containing the G93A mutation that causes hereditary ALS (Bendotti et al., 2001) or transgenic rats expressing the same mutation (Howland et al., 2002). Interestingly, whereas Bendotti found a late decrease in EAAT2 expression at the time when the mice have already become symptomatic (Bendotti et al., 2001), Howland et al. reported changes in EAAT2 expression in the presymptomatic stage (Howland et al., 2002). The $\beta$-lactam antibiotic ceftriaxone (Cef) induces EAAT2 in cultured murine spinal cord slices (Rothstein et al., 2005) and in neuron/astrocyte co-cultures (Lewerenz et al., 2009). It also induced EAAT2 expression in the spinal cords of wild-type and mutant G93A mSOD1 Tg mice, which was associated with a decrease in motor neuron loss, weight loss, and other ALS-like symptoms and an increase in survival (Rothstein et al., 2005), compatible with the idea that EAAT2 loss contributes to chronic excitotoxicity in this mouse model. Just recently, a prominent reduction in EAAT2 immunoreactivity was reported in an independent rodent model for ALS, rats expressing ALSinducing mutant TAR DNA binding protein 43 in astrocytes only (Tong et al., 2013). Interestingly, Alexander et al. found that, when measured by microdialysis, the extracellular L-glu and L-asp concentrations are increased and the L-glu clearance capacity is decreased in the cerebral cortex of G93A mSOD1 Tg mice although this area does not show overt pathology nor downregulation of EAAT1 and 2 when analyzed by Western blotting (Alexander et al., 2000).

Taken together these publications support the view that there is a downregulation of EAAT2 in both human ALS patients and animal models of ALS. However, while some animal studies suggest that EAAT2 downregulation occurs prior to motor neuron loss, others are compatible with the hypothesis that the downregulation of EAAT2, the astroglial expression of which depends on the presence of neurons (Morel et al., 2013), is a consequence of neuronal degeneration.

Whereas, EAATs decrease extracellular L-glu, extracellular cerebral L-glu is upregulated in different brain regions by the cystine/glutamate antiporter system $\mathrm{x}_{\mathrm{c}}^{-}$(De Bundel et al., 2011; Massie et al., 2011). xCT, the specific subunit of system $\mathrm{x}_{\mathrm{c}}^{-}$, was reported to be differentially regulated in mouse models of ALS. Albano et al. (2013) reported that the uptake of radiolabelled cystine was upregulated in spinal cord slices of presymptomatic G93A mSOD1 Tg mice at the age of 70 days but not at 55 or 100 days and not in symptomatic 130 day-old mice and confirmed that the upregulation of cystine uptake at day 70 was due to system $\mathrm{x}_{\mathrm{c}}^{-}$activity using the system $\mathrm{x}_{\mathrm{c}}^{-}$inhibitor sulfasalazine (SSZ). It has to be kept in mind, however, that cystine can also be transported by EAATs (Hayes et al., 2005). Thus, as data about the SSZ-sensitivity of the cystine uptake were not presented for days 100 and 130, the lack of differential cystine uptake found in this study at the older ages might rather be a consequence of decreased EAAT activity. In contrast, Mesci et al. (2015) using rtPCR, demonstrated a robust increase in xCT mRNA levels in G37R mSOD1 Tg mice upon the onset of symptoms, which was further increased as symptoms progressed (Mesci et al., 2015). Moreover, it was demonstrated that xCT was predominantly expressed in spinal cord microglia. When acutely purified from spinal cord, microglia already showed $\mathrm{xCT}$ mRNA upregulation in the presymptomatic phase. Taken together, these findings indicate that system $\mathrm{x}_{\mathrm{c}}^{-}$is upregulated in animal models of ALS. However, evidence is lacking about whether this is also true for human cases of ALS. Nevertheless, Mesci demonstrated that the mRNA levels of CD68, a marker of microglial activation, correlated with xCT mRNA expression in postmortem spinal cord tissue of patients with ALS, suggesting that neuroinflammation in humans is associated with $\mathrm{xCT}$ upregulation (Mesci et al., 2015).

Beyond the dysregulation of L-glu and L-asp levels by EAAT downregulation or system $\mathrm{x}_{\mathcal{c}}^{-}$upregulation, pathways that indirectly modulate glutamatergic neurotransmission have also been proposed to be involved in motor neuron degeneration in ALS. D-Serine levels have been shown to be progressively increased in the spinal cord of G93A mSOD1 Tg mice (Sasabe et al., 2007, 2012). Beginning at disease onset and continuing during the course of the symptomatic phase, D-serine augments NMDA excitotoxicity in motor neurons (Sasabe et al., 2007, 2012). The upregulation of D-serine in the spinal cord was replicated by others (Thompson et al., 2012). Downregulation of the D-serine metabolizing enzyme DAO in the reticulospinal tract was identified as the main mechanism for D-serine upregulation in the spinal cord in ALS mice (Sasabe et al., 2012). In addition, genetic inactivation of DAO in mice leads to motor neuron degeneration (Sasabe et al., 2012) and a deficiency in the $\mathrm{D}$-serine generating enzyme serine racemase prolonged survival in G93A mSOD1 Tg mice although it paradoxically hastened disease onset (Thompson et al., 2012). A heterozygous mutation of DAO has been shown to segregate with the ALS phenotype in a large family with hereditary ALS (Mitchell et al., 2010). 


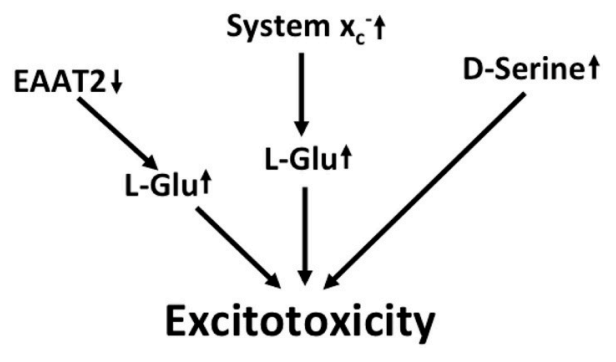

FIGURE 3 | Potential mechanisms that lead to excitotoxicity in ALS. EAAT2 downregulation and upregulation of system $x_{C}^{-}$cause increased activation of glutamate receptors. Moreover, signaling via NMDA receptors is potentiated by the upregulation of the co-activator D-serine.

However, this remains the only family identified so far where a DAO mutation may be linked to the disease (Millecamps et al., 2010).

Regarding the other amino acid co-agonist of the NMDA receptor, glycine, an increase in the CSF levels in patients with ALS was reported by one group (de Belleroche et al., 1984) but could not be replicated by others (Perry et al., 1990; Rothstein et al., 1990). Ilzecka reported that KYNA levels are upregulated in the CSF of bulbar ALS patients and those in end stage disease (Ilzecka et al., 2003). Independently, it was described that tryptophan and KYN levels are increased in the CSF from ALS patients as compared to controls (Chen et al., 2010). In addition, IDO was shown to be expressed in spinal cord microglia and neurons from patients with ALS, indicating that microglial activation could increase the conversion of tryptophan to KYN in ALS.

In summary, multilayered evidence suggests that increased glutamatergic neurotransmission is present in ALS and might contribute to neurodegeneration (Figure 3). Downregulation of EAAT2 in astrocytes and upregulation of system $x_{c}^{-}$in the context of microglial activation has been repeatedly documented. Increased co-activation of NMDA receptors by D-serine might also play a role in glutamatergic dysregulation. In addition, the kynurenine pathway seems to be activated in ALS, most likely in the setting of neuroinflammation.

\section{Alzheimer's Disease}

$\mathrm{AD}$ is the leading cause of dementia in the aging population. Neuropathologically, AD is defined by neurodegeneration with the presence of extracellular senile plaques consisting of $\beta$ amyloid $(A \beta)$ and intraneuronal neurofibrillary tangles consisting of aggregated tau (Grundke-Iqbal et al., 1986; Ingelsson et al., 2004), which first appear in the hippocampus and then spread as the disease progresses. Prominent microglial activation is also a hallmark of AD. Hereditary forms of $\mathrm{AD}$ are caused by mutations in the $A \beta$ precursor protein, $A \beta P P$, or in the presenilins, which are part of the multi-protein complex involved in $A \beta$ generation (Ringman et al., 2014). The pathophysiology of $\mathrm{AD}$ is complex and many pathways are involved in the synaptic and cellular degeneration in AD including abnormalies in signaling pathways via glycogen synthase kinase-3 beta or mitogen-activated protein kinases, cell cycle re-enty (reviewed by Majd et al., 2015), oxidative stress (reviewed by Niedzielska et al., 2015), or decreased transport of trophic factors and mitochondrial dysregulation (reviewed by Overk and Masliah, 2014). However, multiple lines of evidence suggest that L-glu dysregulation also plays a role in AD.

Grilli et al. showed that primary neurons from transgenic mice overexpressing mutant presenilin are more sensitive to excitotoxic stimuli in vitro (Grilli et al., 2000). In vitro, aggregated $\mathrm{A} \beta$ enhances both NMDA and kainate receptor-mediated Lglu toxicity, most likely by interfering with neuronal calcium homeostasis (Mattson et al., 1992). Others have shown that $\mathrm{A} \beta$ can increase neuronal excitability by impairing the ability of glycogen synthase kinase $3 \beta$ inhibition to reduce NMDA receptor-mediated currents (Deng et al., 2014). Moreover, soluble $\mathrm{A} \beta$ oligomers were found to induce L-glu release from astrocytes eventually leading to dendritic spine loss via over-activation of extrasynaptic NMDA receptors (Talantova et al., 2013). Extracellular L-glu concentrations were found to be increased in a triple transgenic mouse model of $\mathrm{AD}$, in which a 3-month treatment with the NMDA receptor inhibitor NitroMemantine rescued synapse loss (Talantova et al., 2013).

A number of mouse studies have shown impacts of $\mathrm{AD}$ like pathology on EAAT expression and/or function. In acute hippocampal slice preparations, $A \beta$ was reported to inhibit the clearance of synaptically released L-glu by decreasing membrane insertion of EAAT2, an effect probably mediated by oxidative stress (Scimemi et al., 2013). In aged A $\beta$ PP23 mice, Schallier et al. observed the downregulation of EAAT2 expression in the frontal cortex and hippocampus, which in the frontal cortex was associated with an increase in xCT expression (Schallier et al., 2011). These changes were associated with a strong tendency toward increased extracellular L-glu levels as measured by microdialysis (Schallier et al., 2011). In triple transgenic AD mice expressing the amyloid precursor protein mutations K670N and $\mathrm{M} 671 \mathrm{~L}$, the presenilin 1 mutation $\mathrm{M} 146 \mathrm{~V}$ and the tau P301L mutation (Oddo et al., 2003; Zumkehr et al., 2015), a strong and age-dependent reduction of EAAT2 expression was found (Zumkehr et al., 2015). Restoration of EAAT2 activity in these $\mathrm{AD}$ mice following treatment with the $\beta$-lactam antibiotic Cef was associated with a decrease in cognitive impairment as well as reduced tau pathology (Zumkehr et al., 2015). In human AD brains, decreased expression of EAAT2 protein as well as a decrease in EAAT activity was described (Li et al., 1997). However, this finding could not be replicated by others (Beckstrøm et al., 1999). Of note, on the transcriptome level, Scott et al. found exon-skipping splice variants of EAAT2 that decrease glutamate transport activity to be upregulated in human AD brains (Scott et al., 2011). In the CSF, some groups found an increase in glutamate concentrations (Pomara et al., 1992; Csernansky et al., 1996; Jimenez-Jimenez et al., 1998; Kaiser et al., 2010) in AD patients, whereas others found no change or even decreased levels (Basun et al., 1990; Martinez et al., 1993; Kuiper et al., 2000).

In vitro, $\mathrm{A} \beta$ induces $\mathrm{L}$-glu release from primary microglia via upregulation of system $x_{\mathcal{c}}^{-}$(Qin et al., 2006). Other found that it also induced L-glu release from astrocytes via activation of the $\alpha 7$ nicotinic acetylcholine receptor (Talantova et al., 2013). In 


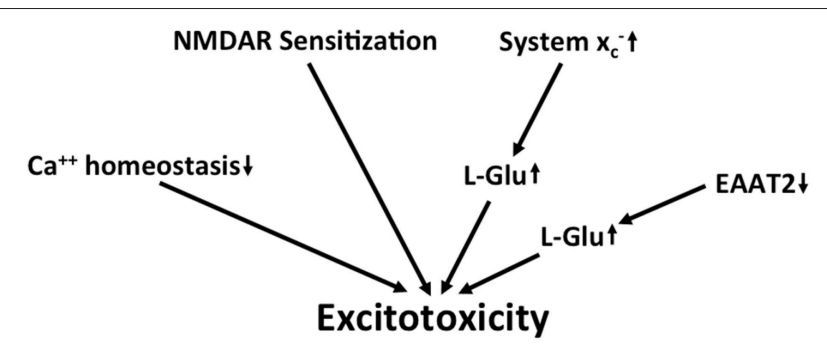

FIGURE 4 | Potential mechanisms that lead to excitotoxicity in AD. Altered calcium homeostasis and increased sensitization of NMDA receptors in $A D$ renders neurons more sensitive to excitotoxicity. This is further amplified by the upregulation of extracellular glutamate via downregulation of EAAT2 and upregulation of system $\mathrm{x}_{\mathrm{C}}^{-}$

addition, $\mathrm{xCT}$, the specific subunit of system $\mathrm{x}_{\mathrm{c}}^{-}$is upregulated in the vicinity of senile plaques, probably in microglia, in Thy1-APP 751 mice (TgAPP) expressing human APP bearing the Swedish (S: KM595/596NL) and London (L: V6421) mutations as well as after $A \beta$ injection in the hippocampus (Qin et al., 2006). Semiquantitative immunoblot analysis revealed an upregulation of $\mathrm{xCT}$ protein expression in the frontal cortex in aged A $\beta$ PP23 mice compared to wild-type controls (Schallier et al., 2011).

Postmortem studies indicate that KYN metabolism might also be modified in $\mathrm{AD}$ as increased concentrations of KYNA were found in the basal ganglia of AD patients (Baran et al., 1999). Using immunohistochemistry, Guillemin et al. found immunoreactivity for both IDO and QUIN upregulated in AD brains, especially in the vicinity of plaques (Guillemin et al., 2005). Of note, $A \beta$ induces IDO expression in human primary macrophages and microglia (Guillemin et al., 2003). Indeed, systemic inhibition of KMO lead to increases in brain KYNA levels and ameliorated the phenotype of a mouse model of $\mathrm{AD}$ (Zwilling et al., 2011), indicating that an upregulation of KYNA might be an endogenous protective response. Also the IDO inhibitor, coptisine, reduced microglial, and astrocytic activation and cognitive impairment in AD mice (Yu et al., 2015).

Taken together, along with several other detrimental changes, there is evidence for chronic excitotoxicity in $\mathrm{AD}$ which may be driven by multiple factors including the sensitization of NMDA receptors, a decrease in L-glu and L-asp reuptake capacity and an increase in glutamate release via system $\mathrm{x}_{\mathrm{c}}^{-}$(Figure 4). Although the KYN pathway seems to be upregulated in $\mathrm{AD}$, no specific conclusions can be drawn regarding glutamatergic neurotransmission from the reported upregulation of both neurotoxic QUIN and neuroprotective KYNA.

\section{Huntington's Disease}

HD is a dominantly inherited, fatal neurodegenerative disease caused by a trinucleotide (CAG) repeat expansion in the coding region of the huntingtin (htt) gene that leads to the degeneration of GABAergic medium-sized spiny neurons (MSN) in the striatum, although other brain regions are also affected as the disease progresses. HD presents as a movement disorder with co-morbid psychiatric and cognitive symptomatology (Nance, 1997). Both mutant htt RNA and the encoded protein that contains a polyglutamine repeat expansion are thought to lead to complex alterations in cellular metabolism culminating in mitochondrial dysfunction and oxidative stress (Ayala-Peña, 2013; Johri et al., 2013; Tsoi and Chan, 2014).

Early findings that suggested that excitotoxicity might play an important role in $\mathrm{HD}$ were based on the observation that injection of the KYN metabolite and NMDA receptor agonist QUIN, as well as L-glu and kainate, into the striatum of rats generated neuronal degeneration (Coyle and Schwarcz, 1976; Beal et al., 1986). Beal et al. reported that QUIN, as compared to NMDA and kainate, induces a rather selective degeneration of the MSNs rather than general neuronal death (Beal et al., 1986), thus strongly resembling the pathology of HD. Later, NMDA receptors were found to be hyperactive and striatal neurons from different HD mouse models, including those transgenic for a yeast artificial chromosome (YAC) that leads to over-expression of full-length htt with extended polyglutamine repeats (Zeron et al., 2002; Shehadeh et al., 2006), R6/2 mice over-expressing htt exon 1 with extended polyglutamine repeats as well as in knock-in mice with increased CAG repeats inserted in the mouse htt gene (Levine et al., 1999), were shown to be sensitized to excitotoxicity in vitro. Of note, in vivo, a sensitization to excitotoxin injection into the striatum was only observed in the transgenic YAC model of HD (Zeron et al., 2002), whereas mice over-expressing mutant htt exon $1, \mathrm{R} 6 / 1$ and R6/2 mice, (Hansson et al., 1999, 2001b) or N171-82Q mice over-expressing mutant exon 1 and parts of exon 2 (Jarabek et al., 2004) or the so-called "shortstop" mouse expressing human N-terminal htt encoded by exon 1 and 2 with a 128 CAG repeat under the htt promoter (Slow et al., 2005) actually developed resistance to striatal excitotoxin injection during aging. However, this acquired neuroprotection is not specific for NMDA receptor agonists but extends to other neurotoxic insults (Hansson et al., 2001a; Petersén et al., 2001) and may represent an adaptive response to cellular stress.

Rat MSN express high levels of NR2A- and NR2B-containing NMDA receptors when compared to interneurons in the striatum (Landwehrmeyer et al., 1995). Correspondingly, NR1 and NR2B mRNA expression in the neostriatum of HD patients was found to be prominently decreased which correlated with the loss of the neurons (Arzberger et al., 1997). Moreover, NMDA receptormediated currents in MSN were demonstrated to be largely sensitive to the NR2B-specific inhibitor ifenprodil (Zeron et al., 2002). In HEK293 cells, over-expression of mutant htt increased NMDA receptor-mediated currents and exacerbated NMDAinduced cell death only when NR2B- but not when NR2Acontaining NMDA receptors were co-expressed (Chen et al., 1999; Zeron et al., 2001). One possible explanation for the increase in NR2B-containing NMDA receptor expression in HD models is that an extended polyglutamine repeat in htt decreases its binding to PSD95, a postsynaptic density protein involved in NMDA and kainate receptor clustering, leading to increased interaction of PSD95 with the NR2B subunit (Sun et al., 2001; Fan et al., 2009). More recently, data have been presented that suggest that not only the subunit composition but also the localization of NMDA receptors might play an important role in the deleterious NMDA receptor activity in HD. Milnerwood et al. 
(2010) showed that in acute striatal slice preparations from YAC transgenic mice with 128 CAG repeats, extrasynaptic NMDA receptors, especially those containing NR2B, are significantly increased compared to slices from wild-type mice and YAC mice expressing htt with $18 \mathrm{CAG}$ repeats. As expected from in vitro studies (Hardingham et al., 2001), this change was associated with reduced CREB phosphorylation (Milnerwood et al., 2010). The increased proportion of NR2B-containing extrasynaptic NMDA receptors was demonstrated to be associated with an increased extrasynaptic localization of PSD95 (Fan et al., 2012). One pathway that might mediate the sensitization to excitotoxic stimuli downstream of the activation of extrasynaptic NMDA receptors was identified as activation of p38 MAPK (Fan et al., 2012). Taken together, multilayered evidence suggests that mutant htt leads to sensitization of MSN to glutamate excitotoxicity in part through a relative redistribution of NMDA receptors, especially those containing an NR2B subunit, from synaptic to extrasynaptic sites.

The activation of extrasynaptic NMDA receptors in acute striatal brain slices can be effectively induced in YAC mice with 128 CAG repeats by facilitating spillover of synaptic glutamate by inhibiting EAATs (Milnerwood et al., 2010). Consequently, it can be hypothesized that decreased EAAT expression might increase activation of extrasynaptic NMDA receptors. Interestingly, using in situ-hybridization, Arzberger et al. found a decrease in astrocytic EAAT2 mRNA expression in the neostriatum of HD patients (Arzberger et al., 1997). EAAT2 function was found to be decreased in striatal synaptosomes of YAC mice overexpressing human htt with $128 \mathrm{CAG}$ repeats as compared to wildtype mice, however no changes in EAAT2 protein expression could be detected. The authors argued that a functionally relevant decrease in EAAT2 activity in the YAC model of HD was due to reduced palmitoylation of the transporter (Huang et al., 2010). In R6/2 mice, others found reduced EAAT2 mRNA and protein expression (Liévens et al., 2001; Behrens et al., 2002; Shin et al., 2005; Estrada-Sánchez et al., 2009) associated with decreased EAAT2 function in synaptosomes (Liévens et al., 2001) or acute cortico-striatal slices (Shin et al., 2005). However, extracellular striatal glutamate concentrations were found to be similar to those of wild-type control mice (Gianfriddo et al., 2004; Shin et al., 2005) and a reduced glutamate clearance capacity in the R6/2 mice could only be revealed by treatment with EAAT inhibitors or glutamate (Behrens et al., 2002; Estrada-Sánchez et al., 2009). A putative explanation for this finding could be a decrease in glutamate release via system $\mathrm{x}_{\mathrm{c}}^{-}$as recently a decrease in $\mathrm{xCT}$, the specific subunit of system $\mathrm{x}_{\mathrm{c}}^{-}$, was demonstrated in the striatum of $\mathrm{R} 6 / 2$ mice at the mRNA and protein levels (Frederick et al., 2014).

As mentioned above, injection of the KYN metabolite QUIN at supraphysiological concentrations was used as an early animal model of HD (Beal et al., 1986). This led to further investigations of KYN metabolism in HD. Interestingly, the QUIN precursor $3 \mathrm{HK}$ exacerbates neurodegeneration in the QUIN HD model (Guidetti and Schwarcz, 1999), while KYNA is protective (Foster et al., 1984; Schwarcz and Pellicciari, 2002). Guidetti et al. found that in early-stage $\mathrm{HD}$, as compared to control and end-stage $\mathrm{HD}$, neostriatal $3 \mathrm{HK}$ and QUIN concentrations were

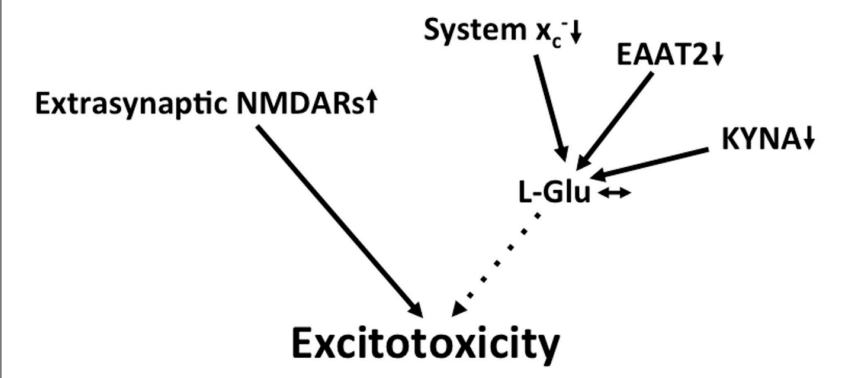

FIGURE 5 | Potential mechanisms that lead to excitotoxicity in HD. Increased redistribution of NMDA receptors to the extrasynaptic compartment is thought to be the prevailing mechanism that fosters excitotoxicity in HD. Although EAAT2 and the glutamate-lowering kynurenine metabolite kynurenic acid (KYNA) are downregulated, these changes might be compensated for by a decrease in system $\mathrm{x}_{\mathrm{C}}^{-}$expression.

significantly upregulated (Guidetti et al., 2004). Another study found KYNA levels decreased in autopsied HD striata as well as in the CSF of HD patients as compared to controls (Beal et al., 1992). The initial enzyme of the KYN pathway, IDO, is induced in the striatum of YAC mice with 128 CAG repeats (Mazarei et al., 2013a). Mice deficient in IDO are less sensitive to intrastriatal QUIN injection (Mazarei et al., 2013b). Analysis of KYN metabolites in different brain regions from three different mouse models of HD, R6/2 mice, YAC128 mice, and HdhQ92 and HdhQ111 knock-in mice, suggested age-dependent activation of the KYN pathway. However, the detailed pattern of metabolite changes differed somewhat among the models with increased $3 \mathrm{HK}$ in cortex, striatum, and cerebellum in R6/2 mice whereas mice expressing full-length mutant htt showed an additional cortical and striatal upregulation of QUIN (Guidetti et al., 2006). Moreover, treatment of R6/2 mice with a non-blood brain barrier permeable KMO inhibitor, JM6, which indirectly increased cerebral extracellular KYNA concentrations by $\sim 50 \%$, was associated with a decrease in extracellular cerebral L-glu, decreased neurodegeneration and prolonged survival (Zwilling et al., 2011).

Taken together, the published literature supports the view that in HD there is a redistribution of NMDA receptors, especially those containing NR2B, which might activate signaling pathways that foster neurodegeneration (Figure 5). There is no consistent evidence that extracellular cerebral L-glu levels are grossly increased in HD. This might be explained by the fact that although EAAT2 and KYNA might be downregulated, there is also a downregulation of system $\mathrm{x}_{c}^{-}$activity. As only very high levels of QUIN activated NMDA receptors, this KYN metabolite is unlikely to directly contribute to the excitotoxic load.

\section{PROOF OF CONCEPT EXPERIMENTS THAT SUPPORT THE HYPOTHESIS OF CHRONIC GLUTAMATE TOXICITY IN NEURODEGENERATION}

As EAATs have been found to be down-regulated in many diseases of the nervous system (Sheldon and Robinson, 2007) 
and hypothetically increased L-glu and L-asp clearance should dampen the excitotoxic component of these diseases, many researchers have set out to identify compounds that induce EAAT2, which is the principal EAAT in the brain and most frequently found to be downregulated (Sheldon and Robinson, 2007; Kim et al., 2011). This has led to the identification of many compounds that in vitro (Colton et al., 2010; Xing et al., 2011) or both in vitro and in vivo (Rothstein et al., 2005; Ganel et al., 2006; Kong et al., 2014) induce astrocytic EAAT2 expression. Some of these have proven to be protective in animal models of neurodegenerative diseases (Rothstein et al., 2005; Ganel et al., 2006; Kong et al., 2014). Cef is perhaps the best studied of these compounds and has been tested in models of AD (Zumkehr et al., 2015), HD (Miller et al., 2008), and ALS (Rothstein et al., 2005) with positive results. However, it has to be kept in mind that none of these compounds has been extensively screened for its ability to interact with other cellular pathways that might also be neuroprotective. Of note, Cef has been shown not only to induce EAAT2 expression but also to activate the transcription factor Nrf2 (Lewerenz et al., 2009), which induces the transcription of a plethora of genes involved in cytoprotection and antioxidant defense (Kensler et al., 2007). Since oxidative stress is assumed to play a role in many, if not all, neurodegenerative diseases (Bogdanov et al., 2001; Radi et al., 2014), this pathway may account for at least some of the neuroprotection induced by Cef. Indeed, $\mathrm{xCT}$, which is one of the downstream targets of $\mathrm{Nrf2}$, has been found to be upregulated by Cef in vitro and in vivo (Lewerenz et al., 2009; Knackstedt et al., 2010). Another in vitro EAAT2-inducing compound, MS153 , effectively protected against secondary neurodegeneration after traumatic brain injury, but through mechanisms other that EAAT2 upregulation (Fontana et al., 2015). Thus, proof of concept experiments that unequivocally demonstrate the pathophysiological role of a chronically increased excitotoxic input via iGluRs in neurodegenerative diseases require more specific manipulations of the neurotransmitter physiology.

As described in the Section on "The Concepts of Acute and Chronic Glutamate Toxicity," Glud1 Tg mice represent a model of chronic excitotoxicity mediated by increased synaptic L-glu release with limited neuronal loss (Bao et al., 2009). However, this animal model of increased glutamatergic neurotransmission has not yet been used to test whether Glud1 over-expression exacerbates the phenotype of mouse models of neurodegenerative diseases. Another genetically engineered model is the EAAT2-deficient mouse. As described in the Section on "The Concepts of Acute and Chronic Glutamate Toxicity," homozygous EAAT2 knock-out mice suffer from premature death due to epilepsy and show hippocampal and focal cortical atrophy (Tanaka et al., 1997; Kiryk et al., 2008; Petr et al., 2015). Heterozygous EAAT2 knock-out mice however develop normally and show only mild behavioral abnormalities (Kiryk et al., 2008). Consequently, this mouse model of mild glutamatergic hyperfunction has been used in a series of proof of principle studies that investigated the functional role of glutamate in animal models of neurodegenerative diseases. ALS mice that carry both the G93A mSOD1 mutation and a reduced amount of EAAT2 (SOD1(G93A)/EAAT2 ${ }^{ \pm}$) exhibited an increase in the rate of motor decline accompanied by earlier motor neuron loss when compared with single mutant G93A mSOD1 $\mathrm{Tg}$ mice (Pardo et al., 2006). A modest reduction in survival was also noted in these double mutant mice. When crossed with transgenic mice expressing mutations of the human amyloid- $\beta$ protein precursor and presenilin-1 (A $\beta$ PPswe/PS1 $\Delta \mathrm{E} 9)$, partial loss of EAAT2 unmasked spatial memory deficits in 6-month-old mice expressing A $\beta P P s w e / P S 1 \triangle E$ 9. These mice also exhibited an increase in the ratio of detergent-insoluble $A \beta 42 / A \beta 40$ suggesting that deficits in glutamate transporter function contribute to early pathogenic processes associated with $\mathrm{AD}$ (Mookherjee et al., 2011). In contrast, the phenotype of the R6/2 HD mouse model was not altered in mice that contained only one EAAT2 allele (Petr et al., 2013).

As a complement to these studies, transgenic mice that overexpress EAAT2 specifically in astrocytes via the GFAP promoter have also been developed (Guo et al., 2003). EAAT2/G93A mSOD1 double Tg mice showed moderate amelioration of the ALS-like phenotype with a statistically significant (14 days) delay in grip strength decline and loss of motor neurons as well as a reduction in other events including caspase-3 activation and SOD1 aggregation but not in the onset of paralysis, body weight decline or an extended life span when compared with monotransgenic G93A mSOD1 littermates (Guo et al., 2003). The same EAAT2 transgenic mouse model was used to test the effect of increased astrocytic L-glu (and L-asp) uptake by cross-breeding with an animal model of $\mathrm{AD}, \mathrm{A} \beta \mathrm{PP}$ swe/Indmice. Increased EAAT2 protein levels significantly improved cognitive function, restored synaptic integrity, and reduced amyloid plaques in these $\mathrm{AD}$ mice (Takahashi et al., 2015).

In mice in which genetically engineered deletion of $\mathrm{xCT}$ leads to deficiency in the glutamate/cystine antiporter system $\mathrm{x}_{\mathrm{c}}^{-}$, the prominent reduction of extrasynaptic L-glu is associated with a robust resistance of dopaminergic neurons against 6hydroxydopamine-induced neurodegeneration (Massie et al., 2011), possibly as a result of decreased excitotoxicity. However, microglial activation has also been shown to be modulated by system $\mathrm{x}_{\mathrm{c}}^{-}$deficiency resulting in a more neuroprotective phenotype (Mesci et al., 2015) which provides an alternative explanation for the protective effect of $\mathrm{xCT}$ deletion in this context.

Thus, genetic models support the role of chronic excitotoxicity in neurodegenerative diseases, especially ALS and AD. Of note, all of these models represent life-long changes in glutamatergic neurotransmission. From the therapeutic perspective, these models cannot predict whether drugs that specifically ameliorate the glutamatergic tone during the neurodegenerative process are protective. To this end, either intensive testing of EAAT2inducing drugs for their interaction with other signaling pathways or the development of inducible mouse models with dampened excitotoxic load are warranted.

\section{SUMMARY}

In summary, "glutamatergic" excitatory input on neurons is a sum of the interaction of several different activators including the direct activators, L-glu, and L-asp, and the co-activators, 
glycine, and D-serine, on iGluRs and mGluRs. Other pathways including tryptophan metabolism and, especially, the tryptophan metabolite KYNA, modulate glutamatergic neurotransmission. Glutamatergic input on neurons is either via synaptically released L-glu (and L-asp) acting on synaptic iGluRs or by non-synaptically released L-glu acting at extrasynaptic L-glu receptors. The glutamate/cystine antiporter, system $x_{c}^{-}$, might be an important determinant of the extrasynaptic cerebral L-glu concentration. Chronically increased input via iGluRs, even if it is only moderate, has the propensity to induce neuronal degeneration, so-called chronic excitotoxicity. In many neurodegenerative diseases, including $\mathrm{HD}, \mathrm{AD}$, and ALS, multilayered evidence suggests that glutamatergic dysregulation is an important contributor to disease pathology although the molecular basis for this varies widely and might be distinct for each disease and most likely does not represent the only pathway that leads to neurodegeneration.

However, as specific pharmacological tools or inducible genetically engineered mouse models that allow manipulation of glutamatergic input are lacking, it is not known to what extent L-glu dysregulation contributes to disease progression in specific mouse models of different neurodegenerative diseases. Thus, while the idea that chronic excitotoxicity contributes

\section{REFERENCES}

Adak, S., Wang, Q., and Stuehr, D. J. (2000). Arginine conversion to nitroxide by tetrahydrobiopterin-free neuronal nitric-oxide synthase. Implications for mechanism. J. Biol. Chem. 275, 33554-33561. doi: 10.1074/jbc.M0043 37200

Ahmadi, S., Muth-Selbach, U., Lauterbach, A., Lipfert, P., Neuhuber, W. L., and Zeilhofer, H. U. (2003). Facilitation of spinal NMDA receptor currents by spillover of synaptically released glycine. Science 300, 2094-2097. doi: 10.1126/science. 1083970

Albano, R., Liu, X., and Lobner, D. (2013). Regulation of system x(c)- in the SOD1-G93A mouse model of ALS. Exp. Neurol. 250, 69-73. doi: 10.1016/j.expneurol.2013.09.008

Alexander, G. M., Deitch, J. S., Seeburger, J. L., Del Valle, L., and Heiman-Patterson, T. D. (2000). Elevated cortical extracellular fluid glutamate in transgenic mice expressing human mutant (G93A) Cu/Zn superoxide dismutase. J. Neurochem. 74, 1666-1673. doi: 10.1046/j.1471-4159.2000.0741666.x

Angulo, M. C., Kozlov, A. S., Charpak, S., and Audinat, E. (2004). Glutamate released from glial cells synchronizes neuronal activity in the hippocampus. J. Neurosci. 24, 6920-6927. doi: 10.1523/JNEUROSCI.0473-04.2004

Arriza, J. L., Fairman, W. A., Wadiche, J. I., Murdoch, G. H., Kavanaugh, M. P., and Amara, S. G. (1994). Functional comparisons of three glutamate transporter subtypes cloned from human motor cortex. J. Neurosci. 14, 5559-5569.

Arzberger, T., Krampfl, K., Leimgruber, S., and Weindl, A. (1997). Changes of NMDA receptor subunit (NR1, NR2B) and glutamate transporter (GLT1) mRNA expression in Huntington's disease-an in situ hybridization study. J. Neuropathol. Exp. Neurol. 56, 440-454. doi: 10.1097/00005072-19970400000013

Ayala-Peña, S. (2013). Role of oxidative DNA damage in mitochondrial dysfunction and Huntington's disease pathogenesis. Free Radic. Biol. Med. 62, 102-110. doi: 10.1016/j.freeradbiomed.2013.04.017

Azbill, R. D., Mu, X., and Springer, J. E. (2000). Riluzole increases high-affinity glutamate uptake in rat spinal cord synaptosomes. Brain Res. 871, 175-180. doi: 10.1016/S0006-8993(00)02430-6

Baker, D. A., McFarland, K., Lake, R. W., Shen, H., Tang, X. C., Toda, S., et al. (2003). Neuroadaptations in cystine-glutamate exchange underlie cocaine relapse. Nat. Neurosci. 6, 743-749. doi: 10.1038/nn1069 to multiple neurodegenerative diseases is supported by many layers of scientific evidence, it is not clear that therapeutic interventions that re-establish glutamatergic homeostasis during ongoing neurodegeneration will be effective tools for stopping the disease process. Besides direct modulators of iGluR activity, strong candidates for future approaches to treating chronic excitotoxicity include specific inducers of EAAT2 to stimulate L-glu and L-asp uptake, inhibitors of system $\mathrm{x}_{\mathrm{c}}^{-}$to reduce L-glu release as well as compounds that aim to decrease extracellular L-glu by modulating KYN metabolism, e.g., KMO inhibitors. In addition, it has to be kept in mind that combinations of these interventions might be required to obtain clinically significant benefits without evoking adverse side effects.

\section{AUTHOR CONTRIBUTIONS}

JL provided the concepts for the review and wrote much of it. PM wrote a portion of the review and edited the entire review.

\section{FUNDING}

PM was partially supported by NIH.

Baker, D. A., Xi, Z. X., Shen, H., Swanson, C. J., and Kalivas, P. W. (2002). The origin and neuronal function of in vivo nonsynaptic glutamate. J. Neurosci. 22, 9134-9141.

Bannai, S., and Ishii, T. (1982). Transport of cystine and cysteine and cell growth in cultured human diploid fibroblasts: effect of glutamate and homocysteate. J. Cell. Physiol. 112, 265-272. doi: 10.1002/jcp.1041120216

Bao, X., Pal, R., Hascup, K. N., Wang, Y., Wang, W. T., Xu, W., et al. (2009). Transgenic expression of Glud1 (glutamate dehydrogenase 1) in neurons: in vivo model of enhanced glutamate release, altered synaptic plasticity, and selective neuronal vulnerability. J. Neurosci. 29, 13929-13944. doi: 10.1523/JNEUROSCI.4413-09.2009

Baran, H., Jellinger, K., and Deecke, L. (1999). Kynurenine metabolism in Alzheimer's disease. J. Neural Transm. 106, 165-181. doi: $10.1007 / \mathrm{s} 007020050149$

Baran, H., and Schwarcz, R. (1990). Presence of 3-hydroxyanthranilic acid in rat tissues and evidence for its production from anthranilic acid in the brain. J. Neurochem. 55, 738-744. doi: 10.1111/j.1471-4159.1990.tb04553.x

Basun, H., Forssell, L. G., Almkvist, O., Cowburn, R. F., Eklöf, R., Winblad, B., et al. (1990). Amino acid concentrations in cerebrospinal fluid and plasma in Alzheimer's disease and healthy control subjects. J. Neural Transm. Park. Dis. Dement. Sect. 2, 295-304. doi: 10.1007/BF02252924

Beal, M. F., Kowall, N. W., Ellison, D. W., Mazurek, M. F., Swartz, K. J., and Martin, J. B. (1986). Replication of the neurochemical characteristics of Huntington's disease by quinolinic acid. Nature 321, 168-171. doi: 10.1038/321168a0

Beal, M. F., Matson, W. R., Storey, E., Milbury, P., Ryan, E. A., Ogawa, T., et al. (1992). Kynurenic acid concentrations are reduced in Huntington's disease cerebral cortex. J. Neurol. Sci. 108, 80-87. doi: 10.1016/0022-510X(92)90191-M

Beckstrøm, H., Julsrud, L., Haugeto, O., Dewar, D., Graham, D. I., Lehre, K. P., et al. (1999). Interindividual differences in the levels of the glutamate transporters GLAST and GLT, but no clear correlation with Alzheimer's disease. J. Neurosci. Res. 55, 218-229.

Behrens, P. F., Franz, P., Woodman, B., Lindenberg, K. S., and Landwehrmeyer, G. B. (2002). Impaired glutamate transport and glutamate-glutamine cycling: downstream effects of the Huntington mutation. Brain 125, 1908-1922. doi: 10.1093/brain/awf180

Bendotti, C., Tortarolo, M., Suchak, S. K., Calvaresi, N., Carvelli, L., Bastone, A., et al. (2001). Transgenic SOD1 G93A mice develop reduced GLT-1 in spinal 
cord without alterations in cerebrospinal fluid glutamate levels. J. Neurochem. 79, 737-746. doi: 10.1046/j.1471-4159.2001.00572.x

Berdichevsky, E., Riveros, N., Sánchez-Armáss, S., and Orrego, F. (1983). Kainate, $\mathrm{N}$-methylaspartate and other excitatory amino acids increase calcium influx into rat brain cortex cells in vitro. Neurosci. Lett. 36, 75-80. doi: 10.1016/03043940(83)90489-5

Berlinguer-Palmini, R., Masi, A., Narducci, R., Cavone, L., Maratea, D., Cozzi, A., et al. (2013). GPR35 activation reduces $\mathrm{Ca}^{2+}$ transients and contributes to the kynurenic acid-dependent reduction of synaptic activity at CA3-CA1 synapses. PLOS ONE 8:e82180. doi: 10.1371/journal.pone.0082180

Bielenberg, G. W., and Beck, T. (1991). The effects of dizocilpine (MK-801), phencyclidine, and nimodipine on infarct size $48 \mathrm{~h}$ after middle cerebral artery occlusion in the rat. Brain Res. 552, 338-342. doi: 10.1016/0006-8993(91) 90101-Z

Birley, S., Collins, J. F., Perkins, M. N., and Stone, T. W. (1982). The effects of cyclic dicarboxylic acids on spontaneous and amino acid-evoked activity of rat cortical neurones. Br. J. Pharmacol. 77, 7-12. doi: 10.1111/j.14765381.1982.tb09262.x

Bogdanov, M. B., Andreassen, O. A., Dedeoglu, A., Ferrante, R. J., and Beal, M. F. (2001). Increased oxidative damage to DNA in a transgenic mouse model of Huntington's disease. J. Neurochem. 79, 1246-1249. doi: 10.1046/j.14714159.2001.00689.x

Brunet, N., Tarabal, O., Esquerda, J. E., and Calderó, J. (2009). Excitotoxic motoneuron degeneration induced by glutamate receptor agonists and mitochondrial toxins in organotypic cultures of chick embryo spinal cord. J. Comp. Neurol. 516, 277-290. doi: 10.1002/cne.22118

Carpenedo, R., Pittaluga, A., Cozzi, A., Attucci, S., Galli, A., Raiteri, M., et al. (2001). Presynaptic kynurenate-sensitive receptors inhibit glutamate release. Eur. J. Neurosci. 13, 2141-2147. doi: 10.1046/j.0953-816x.2001.01592.x

Carriedo, S. G., Yin, H. Z., and Weiss, J. H. (1996). Motor neurons are selectively vulnerable to AMPA/kainate receptor-mediated injury in vitro. J. Neurosci. 16, 4069-4079.

Chaudhry, F. A., Lehre, K. P., van Lookeren Campagne, M., Ottersen, O. P., Danbolt, N. C., and Storm-Mathisen, J. (1995). Glutamate transporters in glial plasma membranes: highly differentiated localizations revealed by quantitative ultrastructural immunocytochemistry. Neuron 15, 711-720. doi: 10.1016/08966273(95)90158-2

Chen, N., Luo, T., Wellington, C., Metzler, M., McCutcheon, K., Hayden, M. R., et al. (1999). Subtype-specific enhancement of NMDA receptor currents by mutant huntingtin. J. Neurochem. 72, 1890-1898. doi: 10.1046/j.14714159.1999.0721890.x

Chen, Y., Stankovic, R., Cullen, K. M., Meininger, V., Garner, B., Coggan, S., et al. (2010). The kynurenine pathway and inflammation in amyotrophic lateral sclerosis. Neurotox. Res. 18, 132-142. doi: 10.1007/s12640-009-9129-7

Choi, D. W. (1988). Glutamate neurotoxicity and diseases of the nervous system. Neuron 1, 623-634. doi: 10.1016/0896-6273(88)90162-6

Choi, D. W. (1992). Excitotoxic cell death. J. Neurobiol. 23, 1261-1276. doi: $10.1002 /$ neu.480230915

Colton, C. K., Kong, Q., Lai, L., Zhu, M. X., Seyb, K. I., Cuny, G. D., et al. (2010). Identification of translational activators of glial glutamate transporter EAAT2 through cell-based high-throughput screening: an approach to prevent excitotoxicity. J. Biomol. Screen. 15, 653-662. doi: 10.1177/1087057110370998

Coulter, D. A., and Eid, T. (2012). Astrocytic regulation of glutamate homeostasis in epilepsy. Glia 60, 1215-1226. doi: 10.1002/glia.22341

Coyle, J. T., and Schwarcz, R. (1976). Lesion of striatal neurones with kainic acid provides a model for Huntington's chorea. Nature 263, 244-246. doi: $10.1038 / 263244 \mathrm{a} 0$

Csernansky, J. G., Bardgett, M. E., Sheline, Y. I., Morris, J. C., and Olney, J. W. (1996). CSF excitatory amino acids and severity of illness in Alzheimer's disease. Neurology 46, 1715-1720. doi: 10.1212/WNL.46.6.1715

Curtis, D. R., Phillis, J. W., and Watkins, J. C. (1960). The chemical excitation of spinal neurones by certain acidic amino acids. J. Physiol. (Lond). 150, 656-682. doi: 10.1113/jphysiol.1960.sp006410

de Belleroche, J., Recordati, A., and Rose, F. C. (1984). Elevated levels of amino acids in the CSF of motor neuron disease patients. Neurochem. Pathol. 2, 1-6. doi: 10.1007/BF02834167

Debono, M. W., Le Guern, J., Canton, T., Doble, A., and Pradier, L. (1993). Inhibition by riluzole of electrophysiological responses mediated by rat kainate and NMDA receptors expressed in Xenopus oocytes. Eur. J. Pharmacol. 235, 283-289. doi: 10.1016/0014-2999(93)90147-A

De Bundel, D., Schallier, A., Loyens, E., Fernando, R., Miyashita, H., Van Liefferinge, J., et al. (2011). Loss of system $\mathrm{x}(\mathrm{c})$ - formula does not induce oxidative stress but decreases extracellular glutamate in hippocampus and influences spatial working memory and limbic seizure susceptibility. J. Neurosci. 31, 5792-5803. doi: 10.1523/JNEUROSCI.5465-10.2011

Deng, Y., Xiong, Z., Chen, P., Wei, J., Chen, S., and Yan, Z. (2014). betaamyloid impairs the regulation of $\mathrm{N}$-methyl-D-aspartate receptors by glycogen synthase kinase 3. Neurobiol. Aging 35, 449-459. doi: 10.1016/j.neurobiolaging.2013.08.031

Dirnagl, U., Iadecola, C., and Moskowitz, M. A. (1999). Pathobiology of ischaemic stroke: an integrated view. Trends Neurosci. 22, 391-397. doi: 10.1016/S01662236(99)01401-0

Do, K. Q., Herrling, P. L., Streit, P., Turski, W. A., and Cuenod, M. (1986). In vitro release and electrophysiological effects in situ of homocysteic acid, an endogenous N-methyl-(D)-aspartic acid agonist, in the mammalian striatum. J. Neurosci. 6, 2226-2234.

Dzubay, J. A., and Jahr, C. E. (1999). The concentration of synaptically released glutamate outside of the climbing fiber-Purkinje cell synaptic cleft. J. Neurosci. $19,5265-5274$

Emnett, C. M., Eisenman, L. N., Taylor, A. M., Izumi, Y., Zorumski, C. F., and Mennerick, S. (2013). Indistinguishable synaptic pharmacodynamics of the Nmethyl-D-aspartate receptor channel blockers memantine and ketamine. Mol. Pharmacol. 84, 935-947. doi: 10.1124/mol.113.089334

Estrada-Sánchez, A. M., Montiel, T., Segovia, J., and Massieu, L. (2009). Glutamate toxicity in the striatum of the R6/2 Huntington's disease transgenic mice is age-dependent and correlates with decreased levels of glutamate transporters. Neurobiol. Dis. 34, 78-86. doi: 10.1016/j.nbd.2008.12.017

Fan, J., Cowan, C. M., Zhang, L. Y., Hayden, M. R., and Raymond, L. A. (2009). Interaction of postsynaptic density protein- 95 with NMDA receptors influences excitotoxicity in the yeast artificial chromosome mouse model of Huntington's disease. J. Neurosci. 29, 10928-10938. doi: 10.1523/JNEUROSCI.2491-09.2009

Fan, J., Gladding, C. M., Wang, L., Zhang, L. Y., Kaufman, A. M., Milnerwood, A. J., et al. (2012). P38 MAPK is involved in enhanced NMDA receptordependent excitotoxicity in YAC transgenic mouse model of Huntington disease. Neurobiol. Dis. 45, 999-1009. doi: 10.1016/j.nbd.2011.12.019

Fogal, B., Li, J., Lobner, D., McCullough, L. D., and Hewett, S. J. (2007). System $\mathrm{x}(\mathrm{c})$ - activity and astrocytes are necessary for interleukin-1 betamediated hypoxic neuronal injury. J. Neurosci. 27, 10094-10105. doi: 10.1523/JNEUROSCI.2459-07.2007

Fonnum, F. (1984). Glutamate: a neurotransmitter in mammalian brain. J. Neurochem. 42, 1-11. doi: 10.1111/j.1471-4159.1984.tb09689.x

Fontana, A. C., Fox, D. P., Zoubroulis, A., Mortensen, O. V., and Raghupathi, R. (2015). Neuroprotective effects of the glutamate transporter activator $(R)$ (-)-5-methyl-1-nicotinoyl-2-pyrazoline (MS-153), following traumatic brain injury in the adult rat. J. Neurotrauma. doi: 10.1089/neu.2015.4079. [Epub ahead of print].

Foster, A. C., Vezzani, A., French, E. D., and Schwarcz, R. (1984). Kynurenic acid blocks neurotoxicity and seizures induced in rats by the related brain metabolite quinolinic acid. Neurosci. Lett. 48, 273-278. doi: 10.1016/0304-3940(84) 90050-8

Frauscher, G., Karnaukhova, E., Muehl, A., Hoeger, H., and Lubec, B. (1995). Oral administration of homocysteine leads to increased plasma triglycerides and homocysteic acid-additional mechanisms in homocysteine induced endothelial damage? Life Sci. 57, 813-817. doi: 10.1016/0024-3205(95)02009-8

Frederick, N. M., Bertho, J., Patel, K. K., Petr, G. T., Bakradze, E., Smith, S. B., et al. (2014). Dysregulation of system xc(-) expression induced by mutant huntingtin in a striatal neuronal cell line and in R6/2 mice. Neurochem. Int. 76, 59-69. doi: 10.1016/j.neuint.2014.06.017

Freire, M. A. (2012). Pathophysiology of neurodegeneration following traumatic brain injury. West Indian Med. J. 61, 751-755.

Fuchs, A., Kutterer, S., Mühling, T., Duda, J., Schütz, B., Liss, B., et al. (2013). Selective mitochondrial $\mathrm{Ca}^{2+}$ uptake deficit in disease endstage vulnerable motoneurons of the SOD1G93A mouse model of amyotrophic lateral sclerosis. J. Physiol. (Lond). 591, 2723-2745. doi: 10.1113/jphysiol.2012.247981

Fukui, S., Schwarcz, R., Rapoport, S. I., Takada, Y., and Smith, Q. R. (1991). Blood-brain barrier transport of kynurenines: implications for brain 
synthesis and metabolism. J. Neurochem. 56, 2007-2017. doi: 10.1111/j.14714159.1991.tb03460.x

Gál, E. M., and Sherman, A. D. (1978). Synthesis and metabolism of Lkynurenine in rat brain. J. Neurochem. 30, 607-613. doi: 10.1111/j.14714159.1978.tb07815.x

Ganel, R., Ho, T., Maragakis, N. J., Jackson, M., Steiner, J. P., and Rothstein, J. D. (2006). Selective up-regulation of the glial Na+-dependent glutamate transporter GLT1 by a neuroimmunophilin ligand results in neuroprotection. Neurobiol. Dis. 21, 556-567. doi: 10.1016/j.nbd.2005. 08.014

Ganong, A. H., and Cotman, C. W. (1986). Kynurenic acid and quinolinic acid act at N-methyl-D-aspartate receptors in the rat hippocampus. J. Pharmacol. Exp. Ther. 236, 293-299.

Ganong, A. H., Lanthorn, T. H., and Cotman, C. W. (1983). Kynurenic acid inhibits synaptic and acidic amino acid-induced responses in the rat hippocampus and spinal cord. Brain Res. 273, 170-174. doi: 10.1016/00068993(83)91108-3

Gianfriddo, M., Melani, A., Turchi, D., Giovannini, M. G., and Pedata, F. (2004). Adenosine and glutamate extracellular concentrations and mitogenactivated protein kinases in the striatum of Huntington transgenic mice. Selective antagonism of adenosine $\mathrm{A} 2 \mathrm{~A}$ receptors reduces transmitter outflow. Neurobiol. Dis. 17, 77-88. doi: 10.1016/j.nbd.2004.05.008

Graham, S. H., Shiraishi, K., Panter, S. S., Simon, R. P., and Faden, A. I. (1990). Changes in extracellular amino acid neurotransmitters produced by focal cerebral ischemia. Neurosci. Lett. 110, 124-130. doi: 10.1016/03043940(90)90799-F

Grant, K. S., Burbacher, T. M., Faustman, E. M., and Gratttan, L. (2010). Domoic acid: neurobehavioral consequences of exposure to a prevalent marine biotoxin. Neurotoxicol. Teratol. 32, 132-141. doi: 10.1016/j.ntt.2009. 09.005

Grilli, M., Diodato, E., Lozza, G., Brusa, R., Casarini, M., Uberti, D., et al. (2000). Presenilin-1 regulates the neuronal threshold to excitotoxicity both physiologically and pathologically. Proc. Natl. Acad. Sci. U.S.A. 97, 12822-12827. doi: 10.1073/pnas.97.23.12822

Grundke-Iqbal, I., Iqbal, K., Tung, Y. C., Quinlan, M., Wisniewski, H. M., and Binder, L. I. (1986). Abnormal phosphorylation of the microtubule-associated protein tau (tau) in Alzheimer cytoskeletal pathology. Proc. Natl. Acad. Sci. U.S.A. 83, 4913-4917. doi: 10.1073/pnas.83.13.4913

Guidetti, P., Bates, G. P., Graham, R. K., Hayden, M. R., Leavitt, B. R., MacDonald, M. E., et al. (2006). Elevated brain 3-hydroxykynurenine and quinolinate levels in Huntington disease mice. Neurobiol. Dis. 23, 190-197. doi: 10.1016/j.nbd.2006.02.011

Guidetti, P., Luthi-Carter, R. E., Augood, S. J., and Schwarcz, R. (2004). Neostriatal and cortical quinolinate levels are increased in early grade Huntington's disease. Neurobiol. Dis. 17, 455-461. doi: 10.1016/j.nbd.2004.07.006

Guidetti, P., and Schwarcz, R. (1999). 3-Hydroxykynurenine potentiates quinolinate but not NMDA toxicity in the rat striatum. Eur. J. Neurosci. 11, 3857-3863. doi: 10.1046/j.1460-9568.1999.00806.x

Guillemin, G. J., Brew, B. J., Noonan, C. E., Takikawa, O., and Cullen, K. M. (2005). Indoleamine 2,3 dioxygenase and quinolinic acid immunoreactivity in Alzheimer's disease hippocampus. Neuropathol. Appl. Neurobiol. 31, 395-404. doi: 10.1111/j.1365-2990.2005.00655.x

Guillemin, G. J., Smythe, G. A., Veas, L. A., Takikawa, O., and Brew, B. J. (2003). A beta 1-42 induces production of quinolinic acid by human macrophages and microglia. Neuroreport 14, 2311-2315. doi: 10.1097/00001756-20031219000005

Gundersen, V., Chaudhry, F. A., Bjaalie, J. G., Fonnum, F., Ottersen, O. P., and Storm-Mathisen, J. (1998). Synaptic vesicular localization and exocytosis of Laspartate in excitatory nerve terminals: a quantitative immunogold analysis in rat hippocampus. J. Neurosci. 18, 6059-6070.

Gundersen, V., Ottersen, O. P., and Storm-Mathisen, J. (1991). Aspartate- and glutamate-like immunoreactivities in rat hippocampal slices: depolarizationinduced redistribution and effects of precursors. Eur. J. Neurosci. 3, 1281-1299. doi: 10.1111/j.1460-9568.1991.tb00061.x

Guo, H., Lai, L., Butchbach, M. E., Stockinger, M. P., Shan, X., Bishop, G. A., et al. (2003). Increased expression of the glial glutamate transporter EAAT2 modulates excitotoxicity and delays the onset but not the outcome of ALS in mice. Hum. Mol. Genet. 12, 2519-2532. doi: 10.1093/hmg/ddg267
Ha, J. S., Lee, C. S., Maeng, J. S., Kwon, K. S., and Park, S. S. (2009). Chronic glutamate toxicity in mouse cortical neuron culture. Brain Res. 1273, 138-143. doi: 10.1016/j.brainres.2009.03.050

Hansson, O., Castilho, R. F., Korhonen, L., Lindholm, D., Bates, G. P., and Brundin, P. (2001a). Partial resistance to malonate-induced striatal cell death in transgenic mouse models of Huntington's disease is dependent on age and CAG repeat length. J. Neurochem. 78, 694-703. doi: 10.1046/j.14714159.2001.00482.x

Hansson, O., Guatteo, E., Mercuri, N. B., Bernardi, G., Li, X. J., Castilho, R. F., et al. (2001b). Resistance to NMDA toxicity correlates with appearance of nuclear inclusions, behavioural deficits and changes in calcium homeostasis in mice transgenic for exon 1 of the huntington gene. Eur. J. Neurosci. 14, 1492-1504. doi: 10.1046/j.0953-816x.2001.01767.x

Hansson, O., Petersén, A., Leist, M., Nicotera, P., Castilho, R. F., and Brundin, P. (1999). Transgenic mice expressing a Huntington's disease mutation are resistant to quinolinic acid-induced striatal excitotoxicity. Proc. Natl. Acad. Sci. U.S.A. 96, 8727-8732. doi: 10.1073/pnas.96.15.8727

Hardingham, G. E., Arnold, F. J., and Bading, H. (2001). Nuclear calcium signaling controls CREB-mediated gene expression triggered by synaptic activity. Nat. Neurosci. 4, 261-267. doi: 10.1038/85109

Hardingham, G. E., Fukunaga, Y., and Bading, H. (2002). Extrasynaptic NMDARs oppose synaptic NMDARs by triggering CREB shut-off and cell death pathways. Nat. Neurosci. 5, 405-414. doi: 10.1038/nn835

Harris, A. Z., and Pettit, D. L. (2007). Extrasynaptic and synaptic NMDA receptors form stable and uniform pools in rat hippocampal slices. J. Physiol. (Lond). 584, 509-519. doi: 10.1113/jphysiol.2007.137679

Hashimoto, A., Kumashiro, S., Nishikawa, T., Oka, T., Takahashi, K., Mito, T., et al. (1993). Embryonic development and postnatal changes in free D-aspartate and D-serine in the human prefrontal cortex. J. Neurochem. 61, 348-351. doi: 10.1111/j.1471-4159.1993.tb03575.x

Hashimoto, A., Nishikawa, T., Hayashi, T., Fujii, N., Harada, K., Oka, T., et al. (1992). The presence of free D-serine in rat brain. FEBS Lett. 296, 33-36. doi: 10.1016/0014-5793(92)80397-Y

Hayes, D., Wiessner, M., Rauen, T., and McBean, G. J. (2005). Transport of L-[14C]cystine and L-[14C]cysteine by subtypes of high affinity glutamate transporters over-expressed in HEK cells. Neurochem. Int. 46, 585-594. doi: 10.1016/j.neuint.2005.03.001

Henneberger, C., Papouin, T., Oliet, S. H., and Rusakov, D. A. (2010). Longterm potentiation depends on release of D-serine from astrocytes. Nature 463, 232-236. doi: 10.1038/nature 08673

Hertz, L. (2006). Glutamate, a neurotransmitter-and so much more. A synopsis of Wierzba III. Neurochem. Int. 48, 416-425. doi: 10.1016/j.neuint.2005. 12.021

Holopainen, I., and Kontro, P. (1989). Uptake and release of glycine in cerebellar granule cells and astrocytes in primary culture: potassium-stimulated release from granule cells is calcium-dependent. J. Neurosci. Res. 24, 374-383. doi: $10.1002 /$ jnr. 490240306

Howland, D. S., Liu, J., She, Y., Goad, B., Maragakis, N. J., Kim, B., et al. (2002). Focal loss of the glutamate transporter EAAT2 in a transgenic rat model of SOD1 mutant-mediated amyotrophic lateral sclerosis (ALS). Proc. Natl. Acad. Sci. U.S.A. 99, 1604-1609. doi: 10.1073/pnas. 032539299

Huang, K., Kang, M. H., Askew, C., Kang, R., Sanders, S. S., Wan, J., et al. (2010). Palmitoylation and function of glial glutamate transporter-1 is reduced in the YAC128 mouse model of Huntington disease. Neurobiol. Dis. 40, 207-215. doi: 10.1016/j.nbd.2010.05.027

Ikonomidou, C., Qin Qin, Y., Labruyere, J., and Olney, J. W. (1996). Motor neuron degeneration induced by excitotoxin agonists has features in common with those seen in the SOD-1 transgenic mouse model of amyotrophic lateral sclerosis. J. Neuropathol. Exp. Neurol. 55, 211-224. doi: 10.1097/00005072199602000-00010

Ilzecka, J., Kocki, T., Stelmasiak, Z., and Turski, W. A. (2003). Endogenous protectant kynurenic acid in amyotrophic lateral sclerosis. Acta Neurol. Scand. 107, 412-418. doi: 10.1034/j.1600-0404.2003.00076.x

Ingelsson, M., Fukumoto, H., Newell, K. L., Growdon, J. H., Hedley-Whyte, E. T., Frosch, M. P., et al. (2004). Early Abeta accumulation and progressive synaptic loss, gliosis, and tangle formation in AD brain. Neurology 62, 925-931. doi: 10.1212/01.WNL.0000115115.98960.37 
Ito, S., and Cherubini, E. (1991). Strychnine-sensitive glycine responses of neonatal rat hippocampal neurones. J. Physiol. (Lond). 440, 67-83. doi: 10.1113/jphysiol.1991.sp018696

Jarabek, B. R., Yasuda, R. P., and Wolfe, B. B. (2004). Regulation of proteins affecting NMDA receptor-induced excitotoxicity in a Huntington's mouse model. Brain 127, 505-516. doi: 10.1093/brain/awh058

Jimenez-Jimenez, F. J., Molina, J. A., Gomez, P., Vargas, C., de Bustos, F., BenitoLeon, J., et al. (1998). Neurotransmitter amino acids in cerebrospinal fluid of patients with Alzheimer's disease. J. Neural Transm. 105, 269-277. doi: $10.1007 / \mathrm{s} 007020050073$

Johnson, J. W., and Ascher, P. (1987). Glycine potentiates the NMDA response in cultured mouse brain neurons. Nature 325, 529-531. doi: 10.1038/325529a0

Johri, A., and Beal, M. F. (2012). Mitochondrial dysfunction in neurodegenerative diseases. J. Pharmacol. Exp. Ther. 342, 619-630. doi: 10.1124/jpet.112.192138

Johri, A., Chandra, A., and Beal, M. F. (2013). PGC-1alpha, mitochondrial dysfunction, and Huntington's disease. Free Radic. Biol. Med. 62, 37-46. doi: 10.1016/j.freeradbiomed.2013.04.016

Kaiser, E., Schoenknecht, P., Kassner, S., Hildebrandt, W., Kinscherf, R., and Schroeder, J. (2010). Cerebrospinal fluid concentrations of functionally important amino acids and metabolic compounds in patients with mild cognitive impairment and Alzheimer's disease. Neurodegener. Dis. 7, 251-259. doi: $10.1159 / 000287953$

Kalbaugh, T. L., Zhang, J., and Diamond, J. S. (2009). Coagonist release modulates NMDA receptor subtype contributions at synaptic inputs to retinal ganglion cells. J. Neurosci. 29, 1469-1479. doi: 10.1523/JNEUROSCI.424008.2009

Karamyan, V. T., and Speth, R. C. (2008). Animal models of BMAA neurotoxicity: a critical review. Life Sci. 82, 233-246. doi: 10.1016/j.lfs.2007.11.020

Katsuta, K., Nakanishi, H., Shirakawa, K., Yoshida, K., Takagi, K., and Tamura, A. (1995). The neuroprotective effect of the novel noncompetitive NMDA antagonist, FR115427 in focal cerebral ischemia in rats. J. Cereb. Blood Flow Metab. 15, 345-348. doi: 10.1038/jcbfm. 1995.40

Kensler, T. W., Wakabayashi, N., and Biswal, S. (2007). Cell survival responses to environmental stresses via the Keap1-Nrf2ARE pathway. Annu. Rev. Pharmacol. Toxicol. 47, 89-116. doi: 10.1146/annurev.pharmtox.46.120604.141046

Kilpatrick, I. C., and Mozley, L. S. (1986). An initial analysis of the regional distribution of excitatory sulphur-containing amino acids in the rat brain. Neurosci. Lett. 72, 189-193. doi: 10.1016/0304-3940(86)90078-9

Kim, K., Lee, S. G., Kegelman, T. P., Su, Z. Z., Das, S. K., Dash, R., et al. (2011). Role of excitatory amino acid transporter-2 (EAAT2) and glutamate in neurodegeneration: opportunities for developing novel therapeutics. J. Cell. Physiol. 226, 2484-2493. doi: $10.1002 /$ jcp.22609

Kiryk, A., Aida, T., Tanaka, K., Banerjee, P., Wilczynski, G. M., Meyza, K., et al. (2008). Behavioral characterization of GLT1 (+/-) mice as a model of mild glutamatergic hyperfunction. Neurotox. Res. 13, 19-30. doi: 10.1007/BF03033364

Kleckner, N. W., and Dingledine, R. (1988). Requirement for glycine in activation of NMDA-receptors expressed in Xenopus oocytes. Science 241, 835-837. doi: $10.1126 /$ science. 2841759

Knackstedt, L. A., Melendez, R. I., and Kalivas, P. W. (2010). Ceftriaxone restores glutamate homeostasis and prevents relapse to cocaine seeking. Biol. Psychiatry 67, 81-84. doi: 10.1016/j.biopsych.2009.07.018

Kong, Q., Chang, L. C., Takahashi, K., Liu, Q., Schulte, D. A., Lai, L., et al. (2014). Small-molecule activator of glutamate transporter EAAT2 translation provides neuroprotection. J. Clin. Invest. 124, 1255-1267. doi: 10.1172/JCI66163

Kuiper, M. A., Teerlink, T., Visser, J. J., Bergmans, P. L., Scheltens, P., and Wolters, E. C. (2000). L-glutamate, L-arginine and L-citrulline levels in cerebrospinal fluid of Parkinson's disease, multiple system atrophy, and Alzheimer's disease patients. J Neural Transm 107, 183-189. doi: 10.1007/s007020050016

Landwehrmeyer, G. B., Standaert, D. G., Testa, C. M., Penney, J. B. Jr., and Young, A. B. (1995). NMDA receptor subunit mRNA expression by projection neurons and interneurons in rat striatum. J. Neurosci. 15, 5297-5307.

Leal, S. S., and Gomes, C. M. (2015). Calcium dysregulation links ALS defective proteins and motor neuron selective vulnerability. Front. Cell. Neurosci. 9:225. doi: $10.3389 /$ fncel.2015.00225

Le Bail, M., Martineau, M., Sacchi, S., Yatsenko, N., Radzishevsky, I., Conrod, S., et al. (2015). Identity of the NMDA receptor coagonist is synapse specific and developmentally regulated in the hippocampus. Proc. Natl. Acad. Sci. U.S.A. 112, E204-E213. doi: 10.1073/pnas.1416668112

Lefauconnier, J. M., Portemer, C., and Chatagner, F. (1976). Free amino acids and related substances in human glial tumours and in fetal brain: comparison with normal adult brain. Brain Res. 117, 105-113. doi: 10.1016/0006-8993(76) 90559-X

Levine, M. S., Klapstein, G. J., Koppel, A., Gruen, E., Cepeda, C., Vargas, M. E., et al. (1999). Enhanced sensitivity to $\mathrm{N}$-methyl-D-aspartate receptor activation in transgenic and knockin mouse models of Huntington's disease. J. Neurosci. Res. 58, 515-532.

Lewerenz, J., Albrecht, P., Tien, M. L., Henke, N., Karumbayaram, S., Kornblum, H. I., et al. (2009). Induction of Nrf2 and xCT are involved in the action of the neuroprotective antibiotic ceftriaxone in vitro. J. Neurochem. 111, 332-343. doi: 10.1111/j.1471-4159.2009.06347.x

Li, S., Mallory, M., Alford, M., Tanaka, S., and Masliah, E. (1997). Glutamate transporter alterations in Alzheimer disease are possibly associated with abnormal APP expression. J. Neuropathol. Exp. Neurol. 56, 901-911. doi: 10.1097/00005072-199708000-00008

Liévens, J. C., Woodman, B., Mahal, A., Spasic-Boscovic, O., Samuel, D., Kerkerian-Le Goff, L., et al. (2001). Impaired glutamate uptake in the R6 Huntington's disease transgenic mice. Neurobiol. Dis. 8, 807-821. doi: 10.1006/nbdi.2001.0430

Lin, C. L., Bristol, L. A., Jin, L., Dykes-Hoberg, M., Crawford, T., Clawson, L., et al. (1998). Aberrant RNA processing in a neurodegenerative disease: the cause for absent EAAT2, a glutamate transporter, in amyotrophic lateral sclerosis. Neuron 20, 589-602. doi: 10.1016/S0896-6273(00)80997-6

Liu, X., Rush, T., Zapata, J., and Lobner, D. (2009). beta-N-methylamino-l-alanine induces oxidative stress and glutamate release through action on system $\mathrm{Xc}(-)$. Exp. Neurol. 217, 429-433. doi: 10.1016/j.expneurol.2009.04.002

Lobner, D., Piana, P. M., Salous, A. K., and Peoples, R. W. (2007). Beta-Nmethylamino-L-alanine enhances neurotoxicity through multiple mechanisms. Neurobiol. Dis. 25, 360-366. doi: 10.1016/j.nbd.2006.10.002

Lodge, D. (2009). The history of the pharmacology and cloning of ionotropic glutamate receptors and the development of idiosyncratic nomenclature. Neuropharmacology 56, 6-21. doi: 10.1016/j.neuropharm.2008.08.006

Loss, C. M., Córdova, S. D., and de Oliveira, D. L. (2012). Ketamine reduces neuronal degeneration and anxiety levels when administered during early life-induced status epilepticus in rats. Brain Res. 1474, 110-117. doi: 10.1016/j.brainres.2012.07.046

Ludolph, A. C., and Spencer, P. S. (1995). Toxic neuropathies and their treatment. Baillieres. Clin. Neurol. 4, 505-527.

Luján, R., Roberts, J. D., Shigemoto, R., Ohishi, H., and Somogyi, P. (1997). Differential plasma membrane distribution of metabotropic glutamate receptors mGluR1 alpha, mGluR2 and mGluR5, relative to neurotransmitter release sites. J. Chem. Neuroanat. 13, 219-241. doi: 10.1016/S0891-0618(97)00051-3

Majd, S., Power, J. H., and Grantham, H. J. (2015). Neuronal response in Alzheimer's and Parkinson's disease: the effect of toxic proteins on intracellular pathways. BMC Neurosci. 16:69. doi: 10.1186/s12868-015-0211-1

Marmiroli, P., and Cavaletti, G. (2012). The glutamatergic neurotransmission in the central nervous system. Curr. Med. Chem. 19, 1269-1276. doi: 10.2174/092986712799462711

Martinez, M., Frank, A., Diez-Tejedor, E., and Hernanz, A. (1993). Amino acid concentrations in cerebrospinal fluid and serum in Alzheimer's disease and vascular dementia. J. Neural Transm. Park. Dis. Dement. Sect. 6, 1-9. doi: 10.1007/BF02252617

Massie, A., Boillée, S., Hewett, S., Knackstedt, L., and Lewerenz, J. (2015). Main path and byways: non-vesicular glutamate release by system $x_{c}^{-}$as an important modifier of glutamatergic neurotransmission. J. Neurochem. doi: 10.1111/jnc.13348. [Epub ahead of print].

Massie, A., Schallier, A., Kim, S. W., Fernando, R., Kobayashi, S., Beck, H., et al. (2011). Dopaminergic neurons of system $\mathrm{x}(\mathrm{c})$-deficient mice are highly protected against 6-hydroxydopamine-induced toxicity. FASEB J. 25, 1359-1369. doi: 10.1096/fj.10-177212

Mattson, M. P., Cheng, B., Davis, D., Bryant, K., Lieberburg, I., and Rydel, R. E. (1992). beta-Amyloid peptides destabilize calcium homeostasis and render human cortical neurons vulnerable to excitotoxicity. J. Neurosci. 12, 376-389. 
Mazarei, G., Budac, D. P., Lu, G., Adomat, H., Tomlinson Guns, E. S., Möller, T., et al. (2013a). Age-dependent alterations of the kynurenine pathway in the YAC128 mouse model of Huntington disease. J. Neurochem. 127, 852-867. doi: 10.1111/jnc. 12350

Mazarei, G., Budac, D. P., Lu, G., Lee, H., Möller, T., and Leavitt, B. R. (2013b). The absence of indoleamine 2,3-dioxygenase expression protects against NMDA receptor-mediated excitotoxicity in mouse brain. Exp. Neurol. 249, 144-148. doi: 10.1016/j.expneurol.2013.08.007

McBean, G. J. (2012). The transsulfuration pathway: a source of cysteine for glutathione in astrocytes. Amino Acids 42, 199-205. doi: 10.1007/s00726-0110864-8

Meldrum, B., and Garthwaite, J. (1990). Excitatory amino acid neurotoxicity and neurodegenerative disease. Trends Pharmacol. Sci. 11, 379-387. doi: 10.1016/0165-6147(90)90184-A

Meldrum, B. S. (1994). The role of glutamate in epilepsy and other CNS disorders. Neurology 44, S14-23.

Melendez, R. I., Vuthiganon, J., and Kalivas, P. W. (2005). Regulation of extracellular glutamate in the prefrontal cortex: focus on the cystine glutamate exchanger and group I metabotropic glutamate receptors. J. Pharmacol. Exp. Ther. 314, 139-147. doi: 10.1124/jpet.104.081521

Mesci, P., Zaïdi, S., Lobsiger, C. S., Millecamps, S., Escartin, C., Seilhean, D., et al. (2015). System xC- is a mediator of microglial function and its deletion slows symptoms in amyotrophic lateral sclerosis mice. Brain 138, 53-68. doi: 10.1093/brain/awu312

Millecamps, S., Da Barroca, S., Cazeneuve, C., Salachas, F., Pradat, P. F., DanelBrunaud, V., et al. (2010). Questioning on the role of D amino acid oxidase in familial amyotrophic lateral sclerosis. Proc. Natl. Acad. Sci. U.S.A. 107, E107; author reply E108. doi: 10.1073/pnas.1006190107

Miller, B. R., Dorner, J. L., Shou, M., Sari, Y., Barton, S. J., Sengelaub, D. R., et al. (2008). Up-regulation of GLT1 expression increases glutamate uptake and attenuates the Huntington's disease phenotype in the R6/2 mouse. Neuroscience 153, 329-337. doi: 10.1016/j.neuroscience.2008.02.004

Miller, R. G., Mitchell, J. D., and Moore, D. H. (2012). Riluzole for amyotrophic lateral sclerosis (ALS)/motor neuron disease (MND). Cochrane Database Syst. Rev. 3:CD001447. doi: 10.1002/14651858.CD001447.pub3

Milnerwood, A. J., Gladding, C. M., Pouladi, M. A., Kaufman, A. M., Hines, R. M., Boyd, J. D., et al. (2010). Early increase in extrasynaptic NMDA receptor signaling and expression contributes to phenotype onset in Huntington's disease mice. Neuron 65, 178-190. doi: 10.1016/j.neuron.2010.01.008

Mitani, A., and Tanaka, K. (2003). Functional changes of glial glutamate transporter GLT-1 during ischemia: an in vivo study in the hippocampal CA1 of normal mice and mutant mice lacking GLT-1. J. Neurosci. 23, 7176-7182.

Mitchell, J., Paul, P., Chen, H. J., Morris, A., Payling, M., Falchi, M., et al. (2010). Familial amyotrophic lateral sclerosis is associated with a mutation in D-amino acid oxidase. Proc. Natl. Acad. Sci. U.S.A. 107, 7556-7561. doi: 10.1073/pnas.0914128107

Miyamoto, E. (2006). Molecular mechanism of neuronal plasticity: induction and maintenance of long-term potentiation in the hippocampus. J. Pharmacol. Sci. 100, 433-442. doi: 10.1254/jphs.CPJ06007X

Monyer, H., Burnashev, N., Laurie, D. J., Sakmann, B., and Seeburg, P. H. (1994). Developmental and regional expression in the rat brain and functional properties of four NMDA receptors. Neuron 12, 529-540. doi: 10.1016/08966273(94)90210-0

Mookherjee, P., Green, P. S., Watson, G. S., Marques, M. A., Tanaka, K., Meeker, K. D., et al. (2011). GLT-1 loss accelerates cognitive deficit onset in an Alzheimer's disease animal model. J. Alzheimers. Dis. 26, 447-455. doi: 10.3233/JAD-2011110503

Morel, L., Regan, M., Higashimori, H., Ng, S. K., Esau, C., Vidensky, S., et al. (2013). Neuronal exosomal miRNA-dependent translational regulation of astroglial glutamate transporter GLT1. J. Biol. Chem. 288, 7105-7116. doi: 10.1074/jbc.M112.410944

Moroni, F., Russi, P., Carlá, V., and Lombardi, G. (1988). Kynurenic acid is present in the rat brain and its content increases during development and aging processes. Neurosci. Lett. 94, 145-150. doi: 10.1016/0304-3940(88)90285-6

Mothet, J. P., Pollegioni, L., Ouanounou, G., Martineau, M., Fossier, P., and Baux, G. (2005). Glutamate receptor activation triggers a calcium-dependent and SNARE protein-dependent release of the gliotransmitter D-serine. Proc. Natl. Acad. Sci. U.S.A. 102, 5606-5611. doi: 10.1073/pnas.0408483102
Nance, M. A. (1997). Clinical aspects of CAG repeat diseases. Brain Pathol. 7, 881-900. doi: 10.1111/j.1750-3639.1997.tb00892.x

Niedzielska, E., Smaga, I., Gawlik, M., Moniczewski, A., Stankowicz, P., Pera, J., et al. (2015). Oxidative stress in neurodegenerative diseases. Mol. Neurobiol. 1-32. doi: 10.1007/s12035-015-9337-5

Oddo, S., Caccamo, A., Shepherd, J. D., Murphy, M. P., Golde, T. E., Kayed, R., et al. (2003). Triple-transgenic model of Alzheimer's disease with plaques and tangles: intracellular Abeta and synaptic dysfunction. Neuron 39, 409-421. doi: 10.1016/S0896-6273(03)00434-3

Olney, J. W. (1986). Inciting excitotoxic cytocide among central neurons. Adv. Exp. Med. Biol. 203, 631-645. doi: 10.1007/978-1-4684-7971-3_48

Overk, C. R., and Masliah, E. (2014). Pathogenesis of synaptic degeneration in Alzheimer's disease and Lewy body disease. Biochem. Pharmacol. 88, 508-516. doi: 10.1016/j.bcp.2014.01.015

Palaiologos, G., Hertz, L., and Schousboe, A. (1988). Evidence that aspartate aminotransferase activity and ketodicarboxylate carrier function are essential for biosynthesis of transmitter glutamate. J. Neurochem. 51, 317-320. doi: 10.1111/j.1471-4159.1988.tb04872.x

Paleacu, D., Cohn, D. F., and Rabey, J. M. (1999). Cognitive evaluation of patients with chronic neurolathyrism. Parkinsonism Relat. Disord. 5, 55-58. doi: 10.1016/S1353-8020(99)00016-4

Paoletti, P., and Neyton, J. (2007). NMDA receptor subunits: function and pharmacology. Curr. Opin. Pharmacol. 7, 39-47. doi: 10.1016/j.coph.2006.08.011

Papouin, T., Ladépêche, L., Ruel, J., Sacchi, S., Labasque, M., Hanini, M., et al. (2012). Synaptic and extrasynaptic NMDA receptors are gated by different endogenous coagonists. Cell 150, 633-646. doi: 10.1016/j.cell.2012.06.029

Papouin, T., and Oliet, S. H. (2014). Organization, control and function of extrasynaptic NMDA receptors. Philos. Trans. R. Soc. Lond. B Biol. Sci. 369:20130601. doi: 10.1098/rstb.2013.0601

Pardo, A. C., Wong, V., Benson, L. M., Dykes, M., Tanaka, K., Rothstein, J. D., et al. (2006). Loss of the astrocyte glutamate transporter GLT1 modifies disease in SOD1(G93A) mice. Exp. Neurol. 201, 120-130. doi: 10.1016/j.expneurol.2006.03.028

Park, C. K., Nehls, D. G., Graham, D. I., Teasdale, G. M., and McCulloch, J. (1988). The glutamate antagonist MK-801 reduces focal ischemic brain damage in the rat. Ann. Neurol. 24, 543-551. doi: 10.1002/ana.410240411

Pascual, O., Casper, K. B., Kubera, C., Zhang, J., Revilla-Sanchez, R., Sul, J. Y., et al. (2005). Astrocytic purinergic signaling coordinates synaptic networks. Science 310, 113-116. doi: 10.1126/science. 1116916

Patel, S. A., Warren, B. A., Rhoderick, J. F., and Bridges, R. J. (2004). Differentiation of substrate and non-substrate inhibitors of transport system xc(-): an obligate exchanger of L-glutamate and L-cystine. Neuropharmacology 46, 273-284. doi: 10.1016/j.neuropharm.2003.08.006

Patneau, D. K., and Mayer, M. L. (1990). Structure-activity relationships for amino acid transmitter candidates acting at $\mathrm{N}$-methyl-D-aspartate and quisqualate receptors. J. Neurosci. 10, 2385-2399.

Perry, T. L., Hansen, S., Berry, K., Mok, C., and Lesk, D. (1971). Free amino acids and related compounds in biopsies of human brain. J. Neurochem. 18, 521-528. doi: 10.1111/j.1471-4159.1971.tb11980.x

Perry, T. L., Krieger, C., Hansen, S., and Eisen, A. (1990). Amyotrophic lateral sclerosis: amino acid levels in plasma and cerebrospinal fluid. Ann. Neurol. 28, 12-17. doi: 10.1002/ana.410280105

Petersén, A., Hansson, O., Puschban, Z., Sapp, E., Romero, N., Castilho, R. F., et al. (2001). Mice transgenic for exon 1 of the Huntington's disease gene display reduced striatal sensitivity to neurotoxicity induced by dopamine and 6-hydroxydopamine. Eur. J. Neurosci. 14, 1425-1435. doi: 10.1046/j.0953816x.2001.01765.x

Petr, G. T., Schultheis, L. A., Hussey, K. C., Sun, Y., Dubinsky, J. M., Aoki, C., et al. (2013). Decreased expression of GLT-1 in the R6/2 model of Huntington's disease does not worsen disease progression. Eur. J. Neurosci. 38, 2477-2490. doi: 10.1111/ejn.12202

Petr, G. T., Sun, Y., Frederick, N. M., Zhou, Y., Dhamne, S. C., Hameed, M. Q., et al. (2015). Conditional deletion of the glutamate transporter GLT-1 reveals that astrocytic GLT-1 protects against fatal epilepsy while neuronal GLT-1 contributes significantly to glutamate uptake into synaptosomes. J. Neurosci. 35, 5187-5201. doi: 10.1523/JNEUROSCI.425514.2015 
Petralia, R. S., Wang, Y. X., Hua, F., Yi, Z., Zhou, A., Ge, L., et al. (2010). Organization of NMDA receptors at extrasynaptic locations. Neuroscience 167, 68-87. doi: 10.1016/j.neuroscience.2010.01.022

Pomara, N., Singh, R., Deptula, D., Chou, J. C., Schwartz, M. B., and LeWitt, P. A. (1992). Glutamate and other CSF amino acids in Alzheimer's disease. Am. J. Psychiatry 149, 251-254. doi: 10.1176/ajp.149.2.251

Pullan, L. M., Olney, J. W., Price, M. T., Compton, R. P., Hood, W. F., Michel, J., et al. (1987). Excitatory amino acid receptor potency and subclass specificity of sulfur-containing amino acids. J. Neurochem. 49, 1301-1307. doi: 10.1111/j.1471-4159.1987.tb10024.x

Qin, S., Colin, C., Hinners, I., Gervais, A., Cheret, C., and Mallat, M. (2006). System Xc- and apolipoprotein E expressed by microglia have opposite effects on the neurotoxicity of amyloid-beta peptide 1-40. J. Neurosci. 26, 3345-3356. doi: 10.1523/JNEUROSCI.5186-05.2006

Qiu, S., Pak, C. W., and Currás-Collazo, M. C. (2006). Sequential involvement of distinct glutamate receptors in domoic acid-induced neurotoxicity in rat mixed cortical cultures: effect of multiple dose/duration paradigms, chronological age, and repeated exposure. Toxicol. Sci. 89, 243-256. doi: 10.1093/toxsci/kfj008

Quinn, C. T., Griener, J. C., Bottiglieri, T., Hyland, K., Farrow, A., and Kamen, B. A. (1997). Elevation of homocysteine and excitatory amino acid neurotransmitters in the CSF of children who receive methotrexate for the treatment of cancer. J. Clin. Oncol. 15, 2800-2806.

Radi, E., Formichi, P., Battisti, C., and Federico, A. (2014). Apoptosis and oxidative stress in neurodegenerative diseases. J. Alzheimers. Dis. 42(Suppl. 3), S125S152. doi: 10.3233/JAD-132738

Ringman, J. M., Goate, A., Masters, C. L., Cairns, N. J., Danek, A., GraffRadford, N., et al. (2014). Genetic heterogeneity in Alzheimer disease and implications for treatment strategies. Curr. Neurol. Neurosci. Rep. 14:499. doi: 10.1007/s11910-014-0499-8

Rosenberg, D., Artoul, S., Segal, A. C., Kolodney, G., Radzishevsky, I., Dikopoltsev, E., et al. (2013). Neuronal D-serine and glycine release via the Asc-1 transporter regulates NMDA receptor-dependent synaptic activity. J. Neurosci. 33, 3533-3544. doi: 10.1523/JNEUROSCI.3836-12.2013

Rothstein, J. D., Dykes-Hoberg, M., Pardo, C. A., Bristol, L. A., Jin, L., Kuncl, R. W., et al. (1996). Knockout of glutamate transporters reveals a major role for astroglial transport in excitotoxicity and clearance of glutamate. Neuron 16, 675-686. doi: 10.1016/S0896-6273(00)80086-0

Rothstein, J. D., Jin, L., Dykes-Hoberg, M., and Kuncl, R. W. (1993). Chronic inhibition of glutamate uptake produces a model of slow neurotoxicity. Proc. Natl. Acad. Sci. U.S.A. 90, 6591-6595. doi: 10.1073/pnas.90.14.6591

Rothstein, J. D., Martin, L. J., and Kuncl, R. W. (1992). Decreased glutamate transport by the brain and spinal cord in amyotrophic lateral sclerosis. N. Engl. J. Med. 326, 1464-1468. doi: 10.1056/NEJM199205283262204

Rothstein, J. D., Patel, S., Regan, M. R., Haenggeli, C., Huang, Y. H., Bergles, D. E., et al. (2005). Beta-lactam antibiotics offer neuroprotection by increasing glutamate transporter expression. Nature 433, 73-77. doi: 10.1038/nature 03180

Rothstein, J. D., Tsai, G., Kuncl, R. W., Clawson, L., Cornblath, D. R., Drachman, D. B., et al. (1990). Abnormal excitatory amino acid metabolism in amyotrophic lateral sclerosis. Ann. Neurol. 28, 18-25. doi: 10.1002/ana.410280106

Sagara, Y., and Schubert, D. (1998). The activation of metabotropic glutamate receptors protects nerve cells from oxidative stress. J. Neurosci. 18, 6662-6671.

Sankar, R., Shin, D. H., Liu, H., Mazarati, A., Pereira de Vasconcelos, A., and Wasterlain, C. G. (1998). Patterns of status epilepticus-induced neuronal injury during development and long-term consequences. J. Neurosci. 18, 8382-8393.

Sasabe, J., Chiba, T., Yamada, M., Okamoto, K., Nishimoto, I., Matsuoka, M., et al. (2007). D-serine is a key determinant of glutamate toxicity in amyotrophic lateral sclerosis. EMBO J. 26, 4149-4159. doi: 10.1038/sj.emboj.7601840

Sasabe, J., Miyoshi, Y., Suzuki, M., Mita, M., Konno, R., Matsuoka, M., et al. (2012). $\mathrm{D}$-amino acid oxidase controls motoneuron degeneration through $\mathrm{D}$-serine. Proc. Natl. Acad. Sci. U.S.A. 109, 627-632. doi: 10.1073/pnas.1114639109

Sasaki, S., Komori, T., and Iwata, M. (2000). Excitatory amino acid transporter 1 and 2 immunoreactivity in the spinal cord in amyotrophic lateral sclerosis. Acta Neuropathol. 100, 138-144. doi: 10.1007/s004019900159

Sato, H., Tamba, M., Ishii, T., and Bannai, S. (1999). Cloning and expression of a plasma membrane cystine/glutamate exchange transporter composed of two distinct proteins. J. Biol. Chem. 274, 11455-11458. doi: $10.1074 /$ jbc.274.17.11455
Schallier, A., Smolders, I., Van Dam, D., Loyens, E., De Deyn, P. P., Michotte, A., et al. (2011). Region- and age-specific changes in glutamate transport in the AbetaPP23 mouse model for Alzheimer's disease. J. Alzheimers. Dis. 24, 287-300. doi: 10.3233/JAD-2011-101005

Schell, M. J., Molliver, M. E., and Snyder, S. H. (1995). D-serine, an endogenous synaptic modulator: localization to astrocytes and glutamate-stimulated release. Proc. Natl. Acad. Sci. U.S.A. 92, 3948-3952. doi: 10.1073/pnas.92.9.3948

Schubert, D., and Piasecki, D. (2001). Oxidative glutamate toxicity can be a component of the excitotoxicity cascade. J. Neurosci. 21, 7455-7462.

Schwarcz, R., and Pellicciari, R. (2002). Manipulation of brain kynurenines: glial targets, neuronal effects, and clinical opportunities. J. Pharmacol. Exp. Ther. 303, 1-10. doi: 10.1124/jpet.102.034439

Schwarcz, R., Whetsell, W. O. Jr., and Mangano, R. M. (1983). Quinolinic acid: an endogenous metabolite that produces axon-sparing lesions in rat brain. Science 219, 316-318. doi: 10.1126/science.6849138

Scimemi, A., Meabon, J. S., Woltjer, R. L., Sullivan, J. M., Diamond, J. S., and Cook, D. G. (2013). Amyloid-beta1-42 slows clearance of synaptically released glutamate by mislocalizing astrocytic GLT-1. J. Neurosci. 33, 5312-5318. doi: 10.1523/JNEUROSCI.5274-12.2013

Scott, H. A., Gebhardt, F. M., Mitrovic, A. D., Vandenberg, R. J., and Dodd, P. R. (2011). Glutamate transporter variants reduce glutamate uptake in Alzheimer's disease. Neurobiol. Aging 32, 553.e1-553.e11. doi: 10.1016/j.neurobiolaging.2010.03.008

Shehadeh, J., Fernandes, H. B., Zeron Mullins, M. M., Graham, R. K., Leavitt, B. R., Hayden, M. R., et al. (2006). Striatal neuronal apoptosis is preferentially enhanced by NMDA receptor activation in YAC transgenic mouse model of Huntington disease. Neurobiol. Dis. 21, 392-403. doi: 10.1016/j.nbd.2005.08.001

Sheldon, A. L., and Robinson, M. B. (2007). The role of glutamate transporters in neurodegenerative diseases and potential opportunities for intervention Neurochem. Int. 51, 333-355. doi: 10.1016/j.neuint.2007.03.012

Shi, Q., Savage, J. E., Hufeisen, S. J., Rauser, L., Grajkowska, E., Ernsberger, P., et al. (2003). L-homocysteine sulfinic acid and other acidic homocysteine derivatives are potent and selective metabotropic glutamate receptor agonists. J. Pharmacol. Exp. Ther. 305, 131-142. doi: 10.1124/jpet.102.047092

Shin, J. Y., Fang, Z. H., Yu, Z. X., Wang, C. E., Li, S. H., and Li, X. J. (2005). Expression of mutant huntingtin in glial cells contributes to neuronal excitotoxicity. J. Cell Biol. 171, 1001-1012. doi: 10.1083/jcb.200508072

Slow, E. J., Graham, R. K., Osmand, A. P., Devon, R. S., Lu, G., Deng, Y., et al. (2005). Absence of behavioral abnormalities and neurodegeneration in vivo despite widespread neuronal huntingtin inclusions. Proc. Natl. Acad. Sci. U.S.A. 102, 11402-11407. doi: 10.1073/pnas.0503634102

Sönmez, A., Sayin, O., Gürgen, S. G., and Çalisir, M. (2015). Neuroprotective effects of MK-801 against traumatic brain injury in immature rats. Neurosci. Lett. 597, 137-142. doi: 10.1016/j.neulet.2015.05.001

Spencer, P. S., Nunn, P. B., Hugon, J., Ludolph, A. C., Ross, S. M., Roy, D. N., et al. (1987). Guam amyotrophic lateral sclerosis-parkinsonism-dementia linked to a plant excitant neurotoxin. Science 237, 517-522. doi: 10.1126/science. 3603037

Spooren, W., Lesage, A., Lavreysen, H., Gasparini, F., and Steckler, T. (2010). Metabotropic glutamate receptors: their therapeutic potential in anxiety. Curr. Top. Behav. Neurosci. 2, 391-413. doi: 10.1007/7854_2010_36

Stehberg, J., Moraga-Amaro, R., Salazar, C., Becerra, A., Echeverría, C., Orellana, J. A., et al. (2012). Release of gliotransmitters through astroglial connexin 43 hemichannels is necessary for fear memory consolidation in the basolateral amygdala. FASEB J. 26, 3649-3657. doi: 10.1096/fj.11-198416

Sun, Y., Savanenin, A., Reddy, P. H., and Liu, Y. F. (2001). Polyglutamineexpanded huntingtin promotes sensitization of N-methyl-D-aspartate receptors via post-synaptic density 95. J. Biol. Chem. 276, 24713-24718. doi: 10.1074/jbc.M103501200

Takahashi, K., Kong, Q., Lin, Y., Stouffer, N., Schulte, D. A., Lai, L., et al. (2015). Restored glial glutamate transporter EAAT2 function as a potential therapeutic approach for Alzheimer's disease. J. Exp. Med. 212, 319-332. doi: $10.1084 /$ jem.20140413

Takamori, S. (2006). VGLUTs: 'exciting' times for glutamatergic research? Neurosci. Res. 55, 343-351. doi: 10.1016/j.neures.2006.04.016

Takeda, K., Ishida, A., Takahashi, K., and Ueda, T. (2012). Synaptic vesicles are capable of synthesizing the VGLUT substrate glutamate from 
alpha-ketoglutarate for vesicular loading. J. Neurochem. 121, 184-196. doi: 10.1111/j.1471-4159.2012.07684.x

Talantova, M., Sanz-Blasco, S., Zhang, X., Xia, P., Akhtar, M. W., Okamoto, S., et al. (2013). Abeta induces astrocytic glutamate release, extrasynaptic NMDA receptor activation, and synaptic loss. Proc. Natl. Acad. Sci. U.S.A. 110, E2518E2527. doi: 10.1073/pnas.1306832110

Tanaka, K., Watase, K., Manabe, T., Yamada, K., Watanabe, M., Takahashi, K., et al. (1997). Epilepsy and exacerbation of brain injury in mice lacking the glutamate transporter GLT-1. Science 276, 1699-1702. doi: 10.1126/science.276.5319.1699

Thompson, M., Marecki, J. C., Marinesco, S., Labrie, V., Roder, J. C., Barger, S. W., et al. (2012). Paradoxical roles of serine racemase and D-serine in the G93A mSOD1 mouse model of amyotrophic lateral sclerosis. J. Neurochem. 120, 598-610. doi: 10.1111/j.1471-4159.2011.07601.x

Tong, J., Huang, C., Bi, F., Wu, Q., Huang, B., Liu, X., et al. (2013). Expression of ALS-linked TDP-43 mutant in astrocytes causes non-cell-autonomous motor neuron death in rats. EMBO J. 32, 1917-1926. doi: 10.1038/emboj.2013.122

Tsoi, H., and Chan, H. Y. (2014). Roles of the nucleolus in the CAG RNA-mediated toxicity. Biochim. Biophys. Acta 1842, 779-784. doi: 10.1016/j.bbadis.2013.11.015

Urenjak, J., and Obrenovitch, T. P. (2000). Kynurenine 3-hydroxylase inhibition in rats: effects on extracellular kynurenic acid concentration and N-methyl-Daspartate-induced depolarisation in the striatum. J. Neurochem. 75, 2427-2433. doi: 10.1046/j.1471-4159.2000.0752427.x

Vargas-Caballero, M., and Robinson, H. P. (2004). Fast and slow voltagedependent dynamics of magnesium block in the NMDA receptor: the asymmetric trapping block model. J. Neurosci. 24, 6171-6180. doi: 10.1523/JNEUROSCI.1380-04.2004

Vécsei, L., Szalárdy, L., Fülöp, F., and Toldi, J. (2013). Kynurenines in the CNS: recent advances and new questions. Nat. Rev. Drug Discov. 12, 64-82. doi: $10.1038 / \mathrm{nrd} 3793$

Vucic, S., Nicholson, G. A., and Kiernan, M. C. (2008). Cortical hyperexcitability may precede the onset of familial amyotrophic lateral sclerosis. Brain 131, 1540-1550. doi: 10.1093/brain/awn071

Wang, F., Smith, N. A., Xu, Q., Goldman, S., Peng, W., Huang, J. H., et al. (2013). Photolysis of caged $\mathrm{Ca}^{2+}$ but not receptor-mediated $\mathrm{Ca}^{2+}$ signaling triggers astrocytic glutamate release. J. Neurosci. 33, 17404-17412. doi: 10.1523/JNEUROSCI.2178-13.2013

Wang, X., Bao, X., Pal, R., Agbas, A., and Michaelis, E. K. (2010). Transcriptomic responses in mouse brain exposed to chronic excess of the neurotransmitter glutamate. BMC Genomics 11:360. doi: 10.1186/1471-2164-11-360

Watase, K., Hashimoto, K., Kano, M., Yamada, K., Watanabe, M., Inoue, Y., et al. (1998). Motor discoordination and increased susceptibility to cerebellar injury in GLAST mutant mice. Eur. J. Neurosci. 10, 976-988. doi: 10.1046/j.14609568.1998.00108.x

Wolfensberger, M., Amsler, U., Cuénod, M., Foster, A. C., Whetsell, W. O. Jr., and Schwarcz, R. (1983). Identification of quinolinic acid in rat and human brain tissue. Neurosci. Lett. 41, 247-252. doi: 10.1016/0304-3940(83)90458-5

Wolosker, H., Sheth, K. N., Takahashi, M., Mothet, J. P., Brady, R. O. Jr., Ferris, C. D., et al. (1999). Purification of serine racemase: biosynthesis of the neuromodulator D-serine. Proc. Natl. Acad. Sci. U.S.A. 96, 721-725. doi: 10.1073/pnas.96.2.721

Wu, Y. W., Grebenyuk, S., McHugh, T. J., Rusakov, D. A., and Semyanov, A. (2012). Backpropagating action potentials enable detection of extrasynaptic glutamate by NMDA receptors. Cell Rep. 1, 495-505. doi: 10.1016/j.celrep.2012.03.007

Xia, P., Chen, H. S., Zhang, D., and Lipton, S. A. (2010). Memantine preferentially blocks extrasynaptic over synaptic NMDA receptor currents in hippocampal autapses. J. Neurosci. 30, 11246-11250. doi: 10.1523/JNEUROSCI.248810.2010

Xing, X., Chang, L. C., Kong, Q., Colton, C. K., Lai, L., Glicksman, M. A., et al. (2011). Structure-activity relationship study of pyridazine derivatives as glutamate transporter EAAT2 activators. Bioorg. Med. Chem. Lett. 21, 5774-5777. doi: 10.1016/j.bmcl.2011.08.009

Yamamoto, S., Morinobu, S., Iwamoto, Y., Ueda, Y., Takei, S., Fujita, Y., et al. (2010). Alterations in the hippocampal glycinergic system in an animal model of posttraumatic stress disorder. J. Psychiatr. Res. 44, 1069-1074. doi: 10.1016/j.jpsychires.2010.03.013

Yu, D., Tao, B. B., Yang, Y. Y., Du, L. S., Yang, S. S., He, X. J., et al. (2015). The IDO inhibitor coptisine ameliorates cognitive impairment in a mouse model of Alzheimer's disease. J. Alzheimers Dis. 43, 291-302. doi: 10.3233/JAD-140414

Yuzaki, M., and Connor, J. A. (1999). Characterization of L-homocysteate-induced currents in Purkinje cells from wild-type and NMDA receptor knockout mice. J. Neurophysiol. 82, 2820-2826.

Zeng, L. H., Ouyang, Y., Gazit, V., Cirrito, J. R., Jansen, L. A., Ess, K. C., et al. (2007). Abnormal glutamate homeostasis and impaired synaptic plasticity and learning in a mouse model of tuberous sclerosis complex. Neurobiol. Dis. 28, 184-196. doi: 10.1016/j.nbd.2007.07.015

Zerangue, N., and Kavanaugh, M. P. (1996). Flux coupling in a neuronal glutamate transporter. Nature 383, 634-637. doi: 10.1038/383634a0

Zeron, M. M., Chen, N., Moshaver, A., Lee, A. T., Wellington, C. L., Hayden, M. R., et al. (2001). Mutant huntingtin enhances excitotoxic cell death. Mol. Cell. Neurosci. 17, 41-53. doi: 10.1006/mcne.2000.0909

Zeron, M. M., Hansson, O., Chen, N., Wellington, C. L., Leavitt, B. R., Brundin, P., et al. (2002). Increased sensitivity to $\mathrm{N}$-methyl-D-aspartate receptor-mediated excitotoxicity in a mouse model of Huntington's disease. Neuron 33, 849-860. doi: 10.1016/S0896-6273(02)00615-3

Zhou, X., Hollern, D., Liao, J., Andrechek, E., and Wang, H. (2013). NMDA receptor-mediated excitotoxicity depends on the coactivation of synaptic and extrasynaptic receptors. Cell Death Dis. 4, e560. doi: 10.1038/cddis.2013.82

Zhou, Y., and Danbolt, N. C. (2013). GABA and Glutamate Transporters in Brain. Front. Endocrinol. (Lausanne) 4:165. doi: 10.3389/fendo.2013.00165

Zhou, Y., and Danbolt, N. C. (2014). Glutamate as a neurotransmitter in the healthy brain. J. Neural. Transm. 121, 799-817. doi: 10.1007/s00702-014-1180-8

Zumkehr, J., Rodriguez-Ortiz, C. J., Cheng, D., Kieu, Z., Wai, T., Hawkins, C., et al. (2015). Ceftriaxone ameliorates tau pathology and cognitive decline via restoration of glial glutamate transporter in a mouse model of Alzheimer's disease. Neurobiol. Aging 36, 2260-2271. doi: 10.1016/j.neurobiolaging.2015.04.005

Zwilling, D., Huang, S. Y., Sathyasaikumar, K. V., Notarangelo, F. M., Guidetti, P., Wu, H. Q., et al. (2011). Kynurenine 3-monooxygenase inhibition in blood ameliorates neurodegeneration. Cell 145, 863-874. doi: 10.1016/j.cell.2011.05.020

Conflict of Interest Statement: The authors declare that the research was conducted in the absence of any commercial or financial relationships that could be construed as a potential conflict of interest.

Copyright (C) 2015 Lewerenz and Maher. This is an open-access article distributed under the terms of the Creative Commons Attribution License (CC BY). The use, distribution or reproduction in other forums is permitted, provided the original author(s) or licensor are credited and that the original publication in this journal is cited, in accordance with accepted academic practice. No use, distribution or reproduction is permitted which does not comply with these terms. 